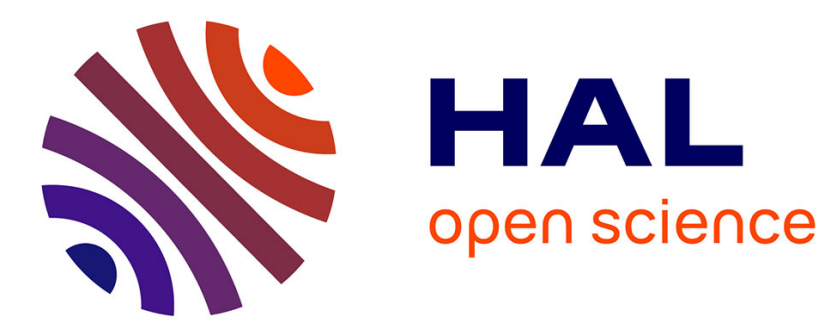

\title{
More than ten years of Blockchain creation: How did we use the technology and which direction is the research heading?
}

\author{
Khalid Ahmed Al-Ansari, Ahmet Faruk Aysan
}

\section{- To cite this version:}

Khalid Ahmed Al-Ansari, Ahmet Faruk Aysan. More than ten years of Blockchain creation: How did we use the technology and which direction is the research heading?. 2021. hal-03343048

\author{
HAL Id: hal-03343048 \\ https://hal.science/hal-03343048
}

Preprint submitted on 13 Sep 2021

HAL is a multi-disciplinary open access archive for the deposit and dissemination of scientific research documents, whether they are published or not. The documents may come from teaching and research institutions in France or abroad, or from public or private research centers.
L'archive ouverte pluridisciplinaire HAL, est destinée au dépôt et à la diffusion de documents scientifiques de niveau recherche, publiés ou non, émanant des établissements d'enseignement et de recherche français ou étrangers, des laboratoires publics ou privés. 


\title{
More than ten years of Blockchain creation: How did we use the technology and which direction is the research heading?
}

\begin{abstract}
To identify how blockchain technology affects current and future research, we carried out a bibliometric overview of the journal articles written on the blockchain. We aimed to answer some of the questions to visualize the trend of the publications regarding the advancement of blockchain utilization in fields relating to finance, economics, and social science. We used the Scopus database for the literature research, which resulted in 506 papers by 1278 authors from 79 countries. Our study showed that from 2008 till 2021, publishing about blockchain was more significant in conference papers than articles by a factor of 2 . Our study also showed the importance of citation regarding published academic articles, the link to the number of publications, the authors, the universities, the affiliated organizations, and the countries of the publications. The use of authoring and citation analysis give valuable insights. On the topic of blockchain, we identified Financial Innovation as the most impactful journal on the topic, the National Natural Science Foundation of China as the leading funding sponsor on blockchain research, the USA as the highest publication production country, and Hong Kong as the highest country in the average citation per document produced. We finally identified the 20 most cited articles on the blockchain topics. Unlike other brief bibliometric studies, our study's investigation and findings could become a first stage of learning for those interested in carrying out a bibliometric study. In addition, our study could become the starting point for any future research on any blockchain projects.
\end{abstract}

Keywords: blockchain, smart contracts, crypto, bitcoin, bibliometric analysis JEL Codes: C21, C22, G11, G14, G17

\author{
Khalid Ahmed Al-Ansari \\ Hamad Bin Khalifa University, \\ College of Islamic Studies, Qatar Foundation, \\ BSc, MBA, LLM, and Doctor of Law \\ khaalansari@hbku.edu.qa \\ orcid.org/0000-0003-2483-6972
}

Ahmet Faruk Aysan

Hamad Bin Khalifa University, Professor \& Program Coordinator Ph.D. in Islamic Finance and Economy

College of Islamic Studies, Qatar Foundation aaysan@hbku.edu.qa orcid.org/0000-0001-7363-0116 


\section{More than ten years of Blockchain creation: How did we use the technology and which direction is the research heading?}

\section{INTRODUCTION}

Many researchers, academics, and technologists had visualized the potential of the blockchain to rewrite the economy's traditional methods and thus changing the balance of power across industries (McLellan, 2019). The most generally accepted definitions for blockchains are that they are distributed public ledgers or a metatechnology: technologies made up of several technologies (Hughes et al, 2019). Blockchain technology was originally introduced to the global community via Bitcoin and was initially relegated for use as a cryptographic mechanism for disseminating bitcoin and associated cryptocurrency transactions (Tandon et al., 2021) to solve the double-spending problem (Ante, 2020). Blockchain's application across multiple sectors, such as supply chain management and the Internet of things, have seen rapid growth in the past five years (Tandon et al., 2021). Other applications experienced growth using the blockchain include healthcare, digital identity, personal data, energy markets, government, voting, law, contracts and the sharing economy (Ante, 2020).

Conway (2020) has explained the blockchain as a specific type of database that differs from a typical database in the way it stores information. Conway showed that blockchain stores data in blocks that are then chained together, and as new data comes in, it is entered into a new block. The author explained that once the block is filled with data, it is chained onto the previous block, making the data chained together in chronological order. Conway showed that different types of information could be stored on a blockchain, but the most common use has been as a ledger for transactions. The author further explained that blockchain is used in a decentralized way in Bitcoin's case so that no single person or group has control -instead, all users collectively retain control. The author finally explained that decentralized blockchains are immutable, which means that the data entered is irreversible, which means for Bitcoin, that transactions are permanently recorded and viewable to anyone. Blockchain is poised to become the most exciting invention after the Internet (Zhao et al., 2016). While the latter connects the world to enable new business models based on online business processes, the former will help resolve the trust issue more efficiently via network computing (Zhao et al., 2016).

In this brief bibliometric study on the blockchain, we attempt to answer some of the questions that enable the reader to visualize the trend of the academic sector publication regarding the advancement of blockchain utilization in all fields relating to human benefits. The study will concentrate on the areas relating to finance, economics, and social science. Most readers who are familiar with the start of the blockchain in 2008 know of the white paper of Satoshi Nakamoto but is it the most referenced paper on the blockchain. Our study is going to explore this.

We attempt to discover whether writing on the topic of blockchain is a relative issue dependent on a specific time frame and may reduce in quantity by time. Will it increase in the future with innovation on the utilization of this technology? The bibliometric analysis will also compare the countries' impact in the field of blockchain publication. It will also evaluate the quality of the publications using the number of citations attracted by an article which is used to assess that article's relative significance in the field (Azer, 2015). 
Our study discovered that conference papers about blockchain exceeded what had been produced in journal articles and books. This high number of conference papers shows the tremendous interest in the topic by conference organizers. We found that computer science was the main subject area of blockchain publication. We also found that China leads the publishing sector in the blockchain, which indicates China's high support for blockchain technology. The USA took the lead in publishing blockchain articles when we searched for articles written in English. We also found that the trend of publication on the topic of blockchain is increasing annually at a progressive rate. This study showed the top 20 blockchain articles that had an impact measured by average citation indicator. In addition, this study showed that Hong Kong generated larger citation counts for the articles published within it than the USA. Furthermore, our study unveiled that the University of Surrey in the UK is leading other universities globally in citations for the articles produced by universities.

By reading many bibliometric studies in different fields, we observed one common denominator with most of them. They give results of the investigation in tables and graphs and a few lines of the summary of the findings. The reader who did not carry out a bibliometric study before would not know how those figures and tables were created and how the results were concluded. We recognized this fact during our literature review. Therefore, in addition to the findings of this study, we also have aimed to rectify the above-stated gap by providing a study that answers our research question and can also help researchers learn and apply the bibliometric analysis concepts in a progressive manner. For more information, the reader may see the following papers (Carvalho et al, 2020); (Bornmann et al, 2020); (Robinson-Garcia et al, 2019) and (Perianes-Rodriguez et al, 2016).

Our study details how the information about journal articles can be extracted from a database source. The database source should be suitable for the research topic. We show how the extracted dataset can be used in the analysis software and then how we reached the results by explaining the steps taken in every stage. The process that we indicate in our study will give the reader the know-how to replicate our investigation, whether it is in the blockchain area or any other field. The reader will learn the concepts and how to apply them, and how to interpret the findings.

Based on the methodology we followed in this study, we hope that this study can be a starting point for any future bibliometric research or any blockchain project. We hope that this study would help to educate future researchers on how to conduct a bibliometric study. In addition, we hope that this study would equip the future researcher in blockchain fields with first-hand information that will facilitate finding the resources for the literature review stage, as well as knowing the influencing countries, authors, universities in the field of blockchain, which may also facilitate further the research process.

The outline of this paper is as follows: the "Methodology and Data" section will explain the different tools that was used in the analysis. "Overview of Blockchain Articles" section will present the searches that was conducted. "Analysis of Authors" section will discuss authors' statistics, networks, funding organizations, publishing organizations, publishers' countries, and present the 20 most cited articles in the field of blockchain. Finally, "Conclusion and Recommendation" section conclude the study with a brief about the obtained results and present recommendation for future research in blockchain and bibliometric analysis. 


\section{METHODOLOGY AND DATA}

Bibliometrics is a quantitative analysis method that uses mathematical and statistical tools to measure the inter-relationships and impacts of publications within a given area of research (Lee et al., 2020). Bibliometric analysis (BMA) unveils pivotal articles and objectively illustrates the linkages between and among articles about a particular research topic or field by analyzing how many times they have been co-cited by other published articles (Fetscherin \& Usunier, 2012).

The BMA makes a vital contribution to the literature, as it outlines, structures, and identifies the key institutions, journals, articles, and authors as well as research streams in linkage to the research (Fetscherin \& Heinrich, 2015). Zhang (n.d.) had divided the process of BMA to includes four modules:

(1) Data acquisition: Data sources from database data and web data, with acquisition methods either manual or automatic.

(2) Data preprocessing: which is mainly format conversion and filtering the data that does not meet the requirements.

(3) Statistical calculation: can be divided into annual growth statistics and other related statistics.

(4) Application analysis.

Accordingly, we modeled our study to align with those modules. We selected a reputable source for the data acquisition (i.e., Scopus). The acquisition method was manual by specifying the search keyword in the data source. We processed the data by selecting filters that eliminated unsuitable data from the search findings data (such as subject areas, document types, and English language). We performed the statistical calculation and analysis using VOSviewer and Biblioshiny software packages.

SCOPUS, over the years, has earned its equal place as a comprehensive bibliographic data source, and it has proven itself to be reliable and, in some respects, even better than Web of Science (Pranckute, 2021). As journal coverage in Scopus is more comprehensive than in Web of Science, this was the prime reason for choosing this particular database (Agarwal et al., 2016). Moreover, as the blockchain topic is scientific, it would be appropriate to search databases with scientific data. The Scopus database is known to provide the most comprehensive overview of the world's research output in science, Technology, Social Sciences, Arts and Humanities, and Medicine (Agarwal et al., 2016).

The selected software analyzed the extracted data from the database source. The type of analysis included the publication year, subject area, publication type, countries, authors, and organizational affiliations. Data were extracted from Scopus and then uploaded into each of the two software to assess the network information about the blockchain. VOSviewer is a software tool for constructing and visualizing bibliometric networks, and those networks may include journals, researchers, or individual publications. The networks can be constructed based on citation, bibliographic coupling, co-citation, or co-authorship relations (VOSviewer Visualizing Scientific Landscapes, n.d.). Biblioshiny is an open-source tool for executing a comprehensive science mapping analysis of scientific literature (Biblioshiny, n.d.). The program is built on the $\mathrm{R}$ Studio Development platform and works within the platform (Bibliometrix R Package, n.d.). 
Searching in the Scopus database source with keyword (blockchain) with filters such as English language and all document types (i.e., conference paper, article, conference review, book chapter, and review) resulted in 18,567 documents. This large number of documents cannot be extracted from the database, as the Scopus database will only allow the extraction of the first 2000 documents' information. By examining the 18,567 documents related to the search word, we see that publication had been consistently increasing for each year since 2014 . Figure 2.1 below shows the increasing trend of publications.

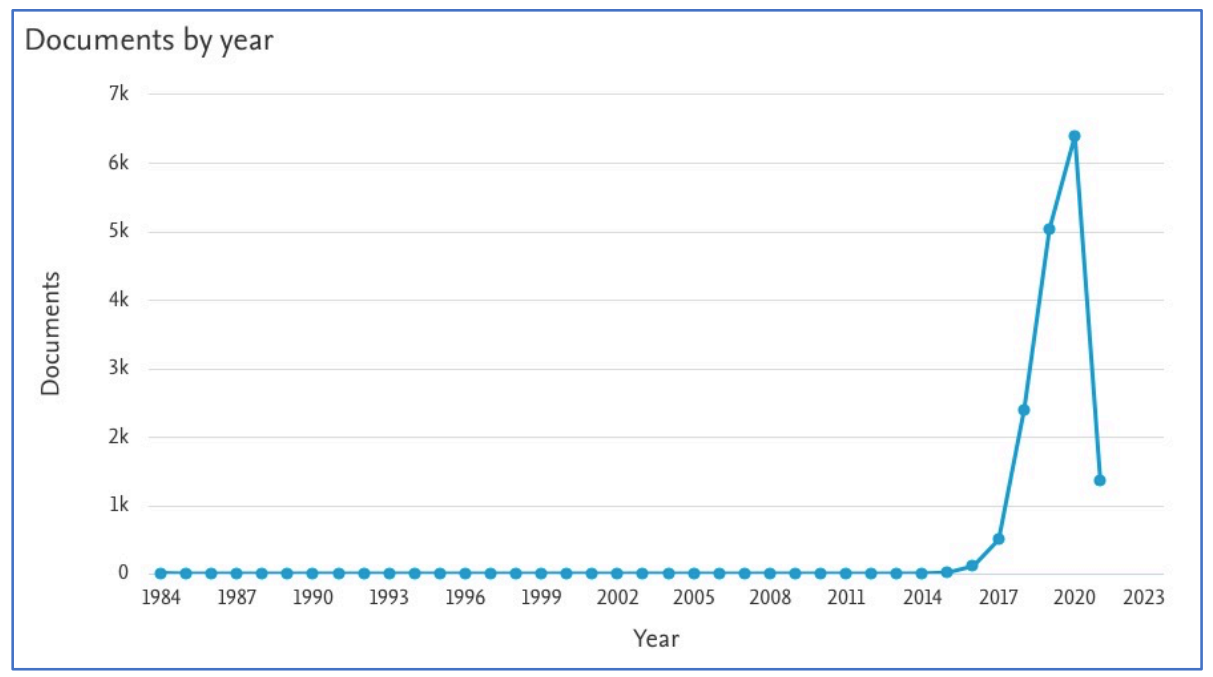

Figure 2.1- Documents Published by Year

Further examination of the extracted data shows that the published documents are covering ten (10) main subject areas, with the most significant subject of publication was in computer science with 12,557 documents (35.7\%), followed by engineering as the second largest area of publication with 6,833 documents $(19.4 \%)$. Decision science came in the third most significant subject area of publication with 3,333 documents (9.5\%), as depicted in Figure 2.2 below.

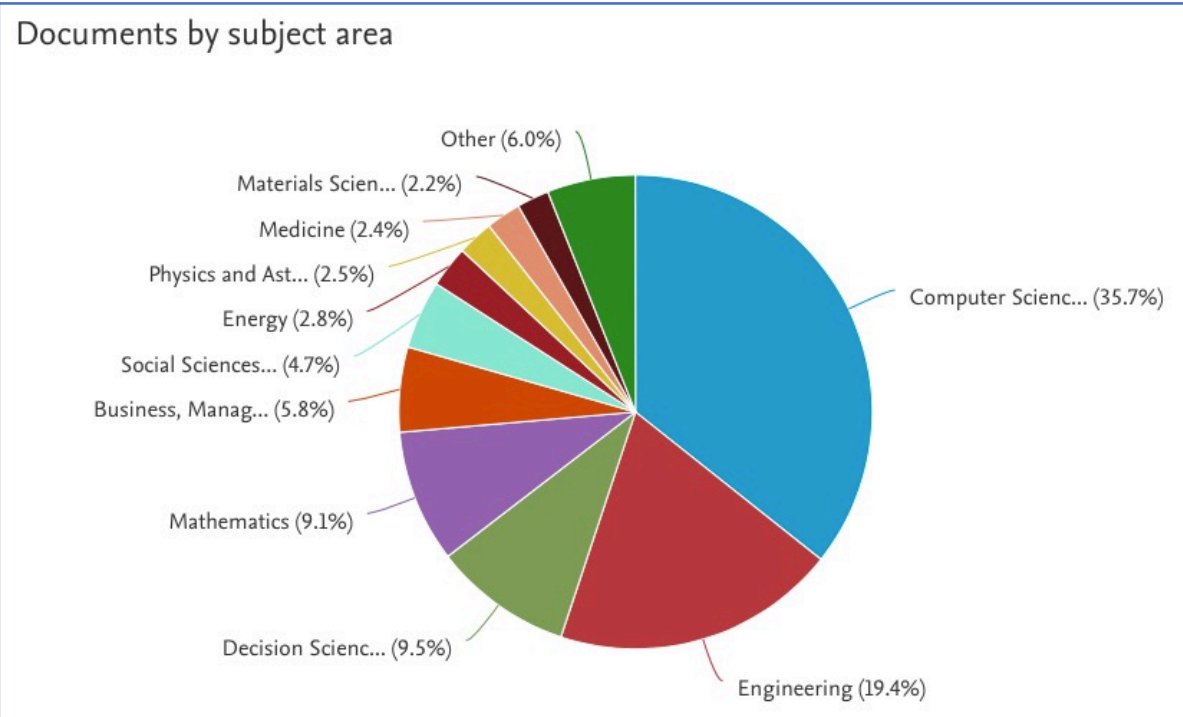

Figure 2.2 - Documents Published by Subject Area 
In examining the type of publications, the extracted information from the database showed that the conference papers take the most significant type with $60.9 \%$, while journal articles coming in the second position with $34.2 \%$, as depicted in Figure 2.3 below.

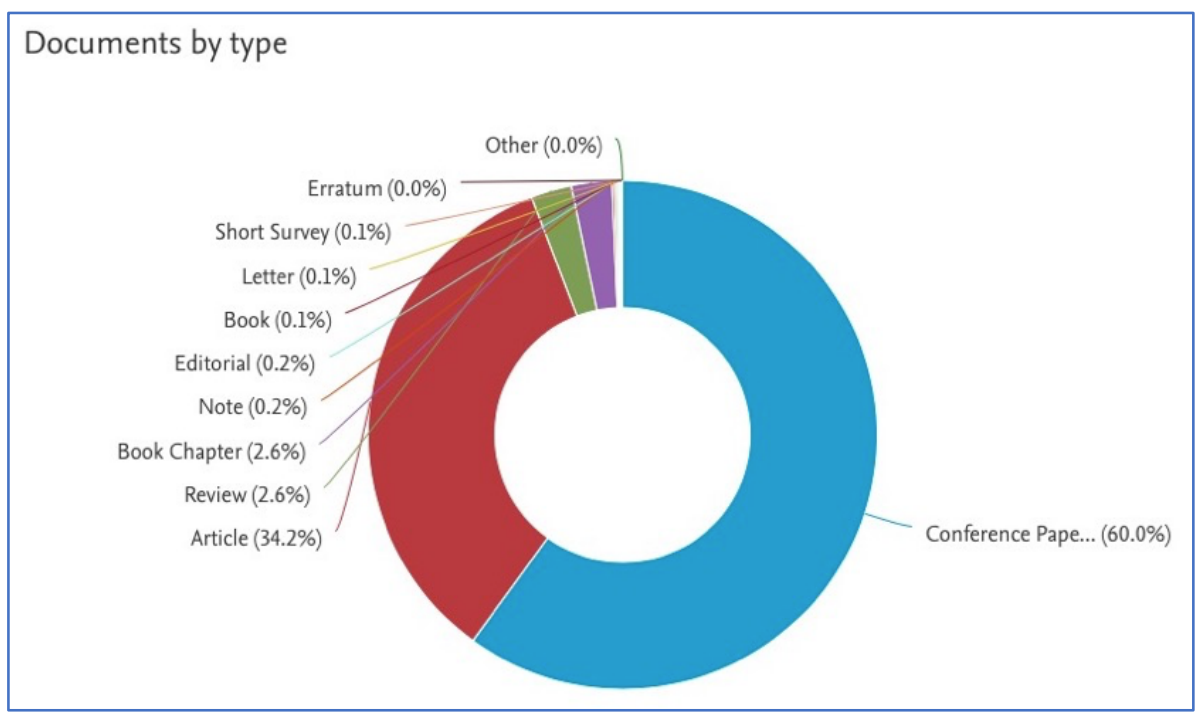

Figure 2.3 - Documents Published by Type

When it comes to countries' publications, we see that China comes in the first spot with 4,138 documents, and the USA comes in the second position with 2,445 documents. India, United Kingdom (UK), and Germany come in the following places with 1,682, 1005, and 712 documents, respectively, as depicted in Figure 2.4 below.

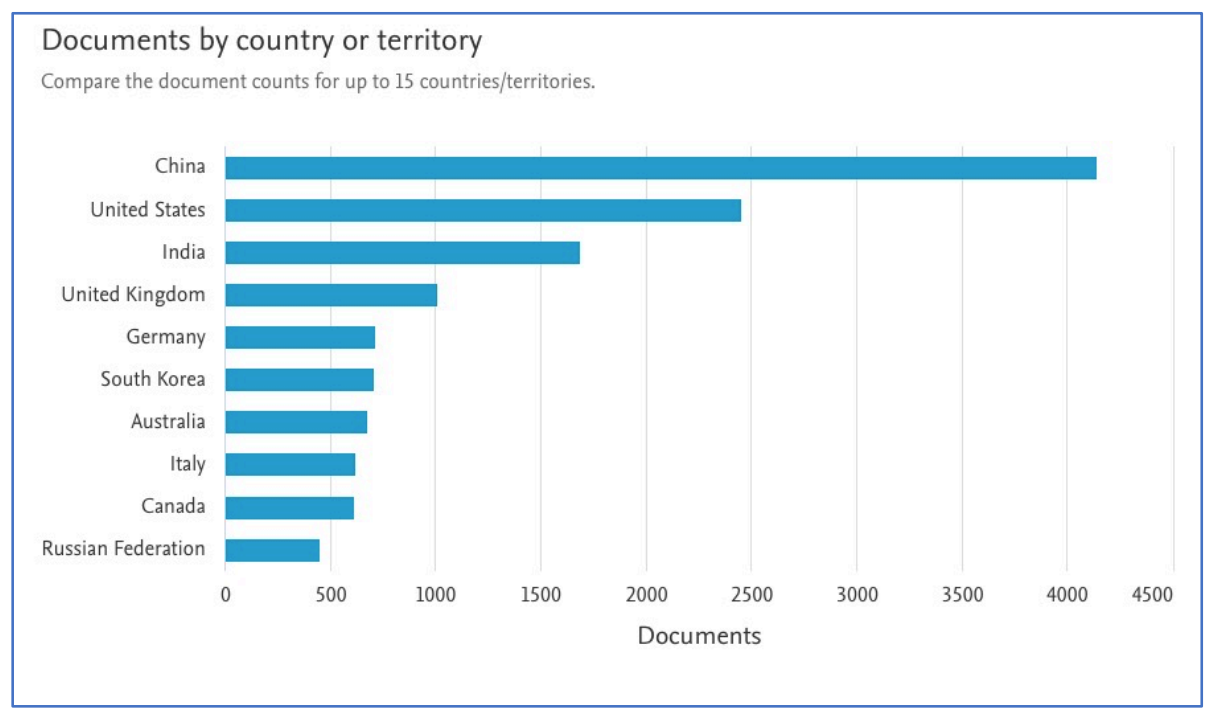

Figure 2.4 - Documents Published by Countries

At this stage, the document tree map is depicted in Figure 2.5, showing each keyword percentage in the search outcome. 


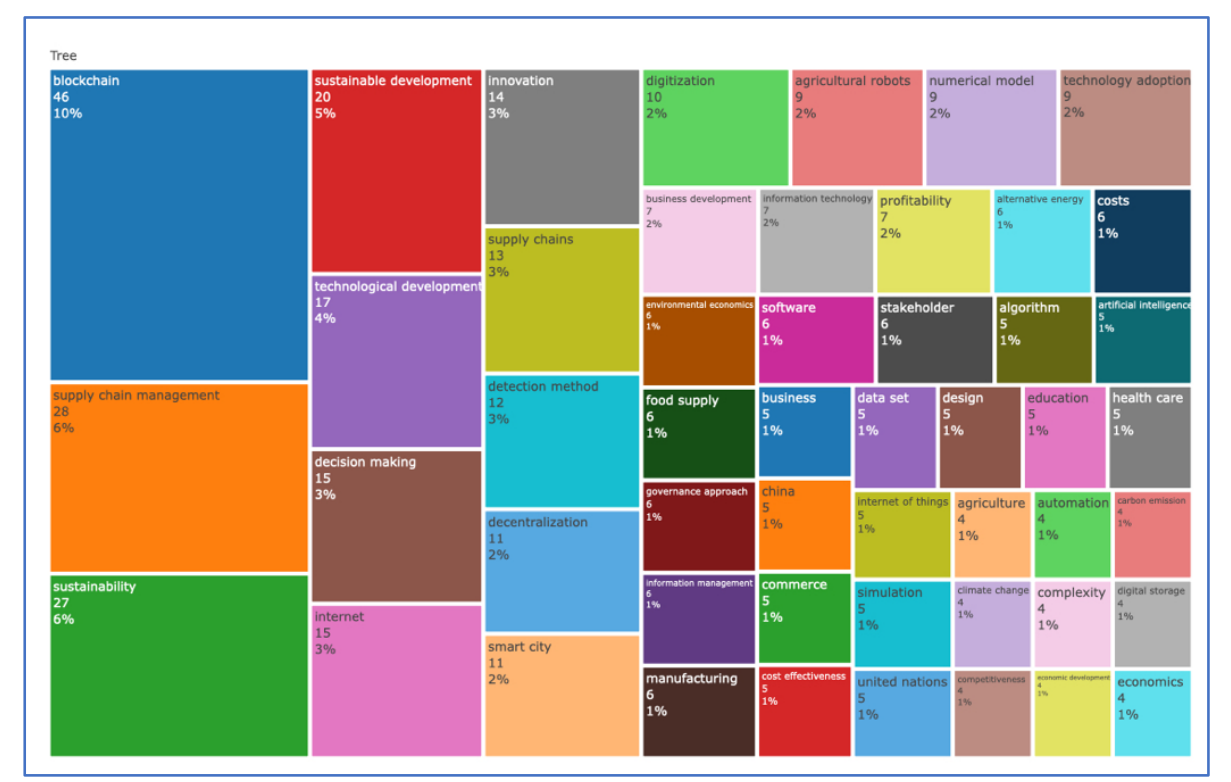

Figure 2.5 - Documents Tree Map

\section{Data Filtering}

As we can see from Figure 2.6 below, that those documents in sizable portions are conference papers $(10,141)$, conference proceedings $(8,354)$, and written in the English language $(18,001)$. However, this large number of documents may include documents from trade journals, books, book series while we are interested in journal findings as a source type. In addition, we can see from earlier Figure 2.2 that the subject areas are including engineering, mathematics, and other areas.

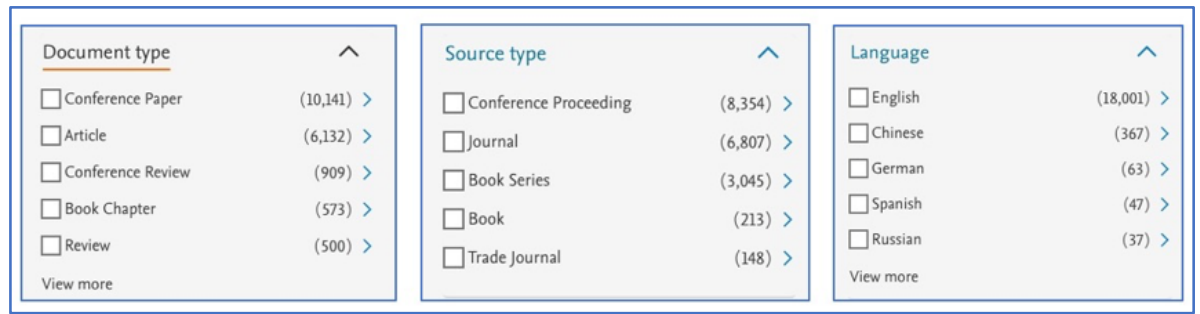

Figure 2.6 - Summary of The First Initial Search in The Database Source

Consequently, we have to limit the research to a credible source type such as journal and document type to be only articles. A refined search in the database source that limited the results to those documents (articles from journals and written in English) resulted in 4,895 documents. We can observe from Figure 2.8 that the countries' numbering had changed when compared with Figure 2.4.

The negative aspect of having such a large set of documents resulting from the search in the database (i.e., 4,895) is that we cannot import the information required for complete analysis from the database source except in citation information format. The citation information format will allow only one type of analysis, Co-authorship with authors as a unit of analysis, which will show the relationship between authors and the link between them. The different types of analysis will not be available. By defining a search query that combines terms that limit the search in business and management disciplines (and related fields), we get a more defined search related to the investigation area. Therefore, the search pattern eliminates the resulting documents from subject areas unrelated to finance, i.e., search coming from nursing, immunology, chemistry, computer science, and chemical engineering. 


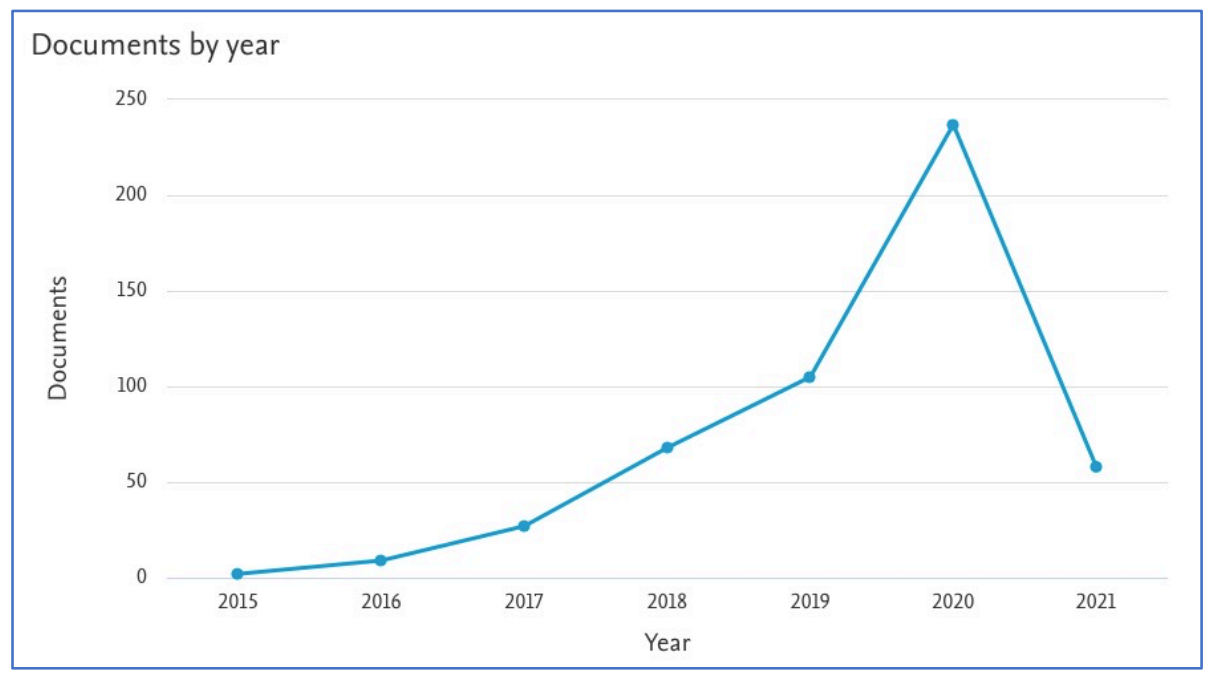

Figure 2.7 - Filtering Effect on Document Number Reduction

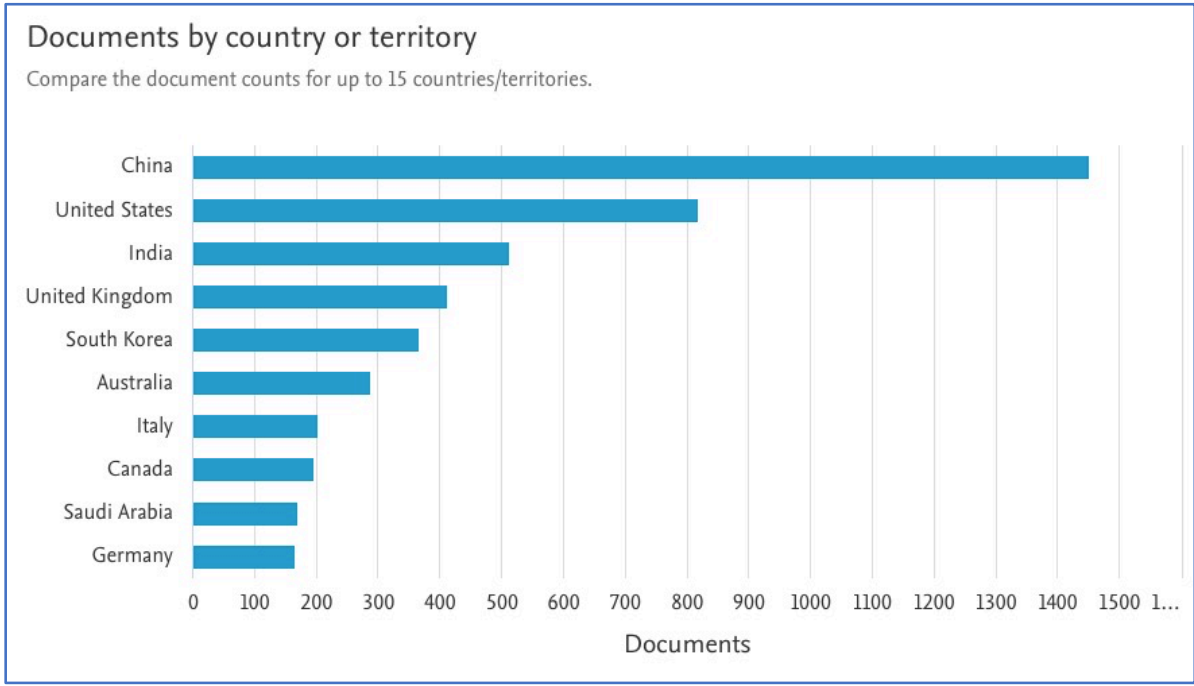

Figure 2.8 - Filtering Effect on Documents by Country

Therefore, filtering the search to subject areas of Business Management \& Accounting, Social Sciences, Economics, Econometrics and Finance, Environmental Science, Energy, and Arts and Humanities, had reduced the resulting documents to 506 documents (as of Thursday 18 March 2021). This result is a reasonable number of documents to start the analysis as it covers the essential subject areas and types of documents.

\section{Bibliometric analysis of the keywords}

When the keyword (blockchain) was used with the earlier discussed filters (as stated earlier), we got the resulting documents reduced to 506. We identified the filtered results of 506 documents on blockchain in the SCOPUS database for all the years. The majority of the documents had been published in 2020 (with 237 articles), which is more than double what has been published in 2019 (with 105 articles). In the first quarter of this year, 2021, 58 articles were published, but it is still early to see the final count. Nevertheless, the observed trend is that the number of published articles increases every year, as depicted in Figure 2.7 earlier.

The filtered result changed the percentage of documents by subject area when compared with the initial search. As we can see from Figure 2.9 below, Economics, Econometrics, and 
Finance lead the way with 301 articles (22.6\%). At the same time, Business, Management, and Accounting come second with 275 articles (20.6\%) which is close to Social Science with 260 articles (19.5\%), followed by Environmental Science with 152 articles (11.4\%), and Energy 145 articles (10.9\%). The Arts and Humanities 43 articles (3.2\%) and Decision Science 38 articles $(2.9 \%)$.

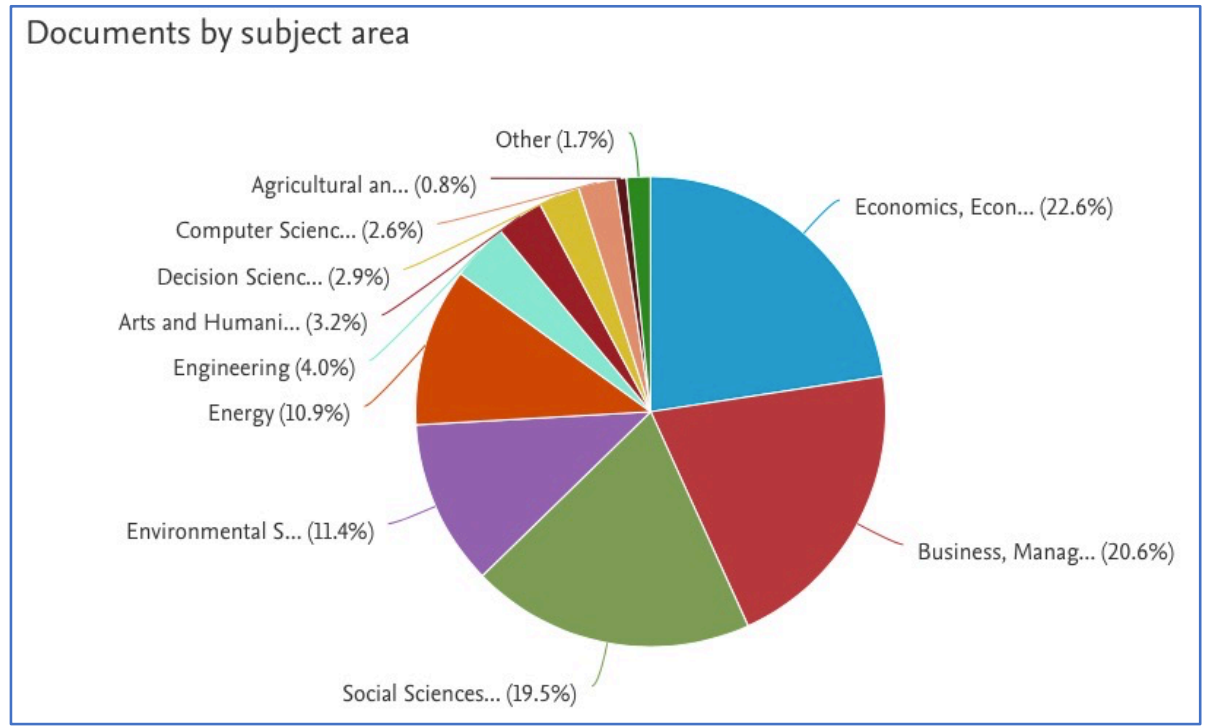

Figure 2.9 - The Subject Area Sectors (Third Search)

The publication type initially included conference papers that were a large proportion of the publication types for blockchain. We can see from Figure 2.10 below that the conference paper percentage published was almost double that of the articles $(60 \%$ compared to $34 \%$, respectively). We refined the result to a lower number of 506 documents when we limited the search type for articles only, which produced results composed of articles only, as shown in Figure 2.11 .

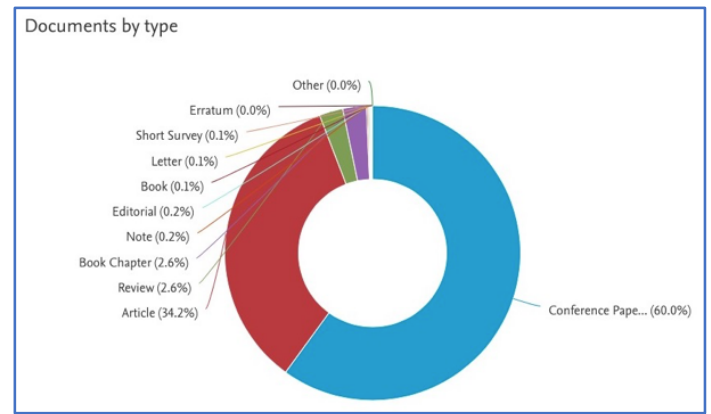

Figure No. 2.10 - Documents By Type Before Using Filters

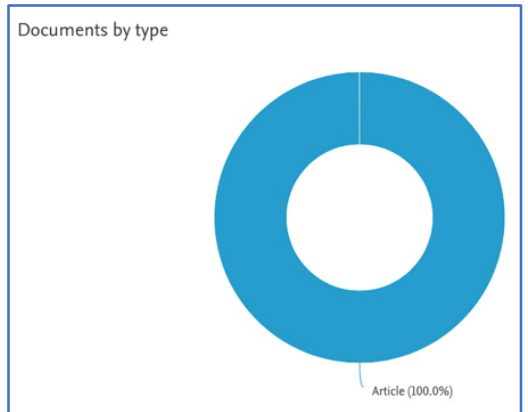

Figure No. 2.11 - Documents By Type After Using Filters

Finally, the filtered result gives the highest number of 5 articles written by Park, J.H. In contrast, Adhami, S., Guidici, G., Irwin, A.S.M., Javid, N., Martinazzi, S., Nikbakht, E. Novak, M., O'Leary, D.E., Parry, G., Turner, A.B., Vismara, S., all have written three articles. The reader can see the above information about the authors and numbers of publications in Figure 2.12 below. The authors who had two articles are 65 authors, while the rest had one article each. 


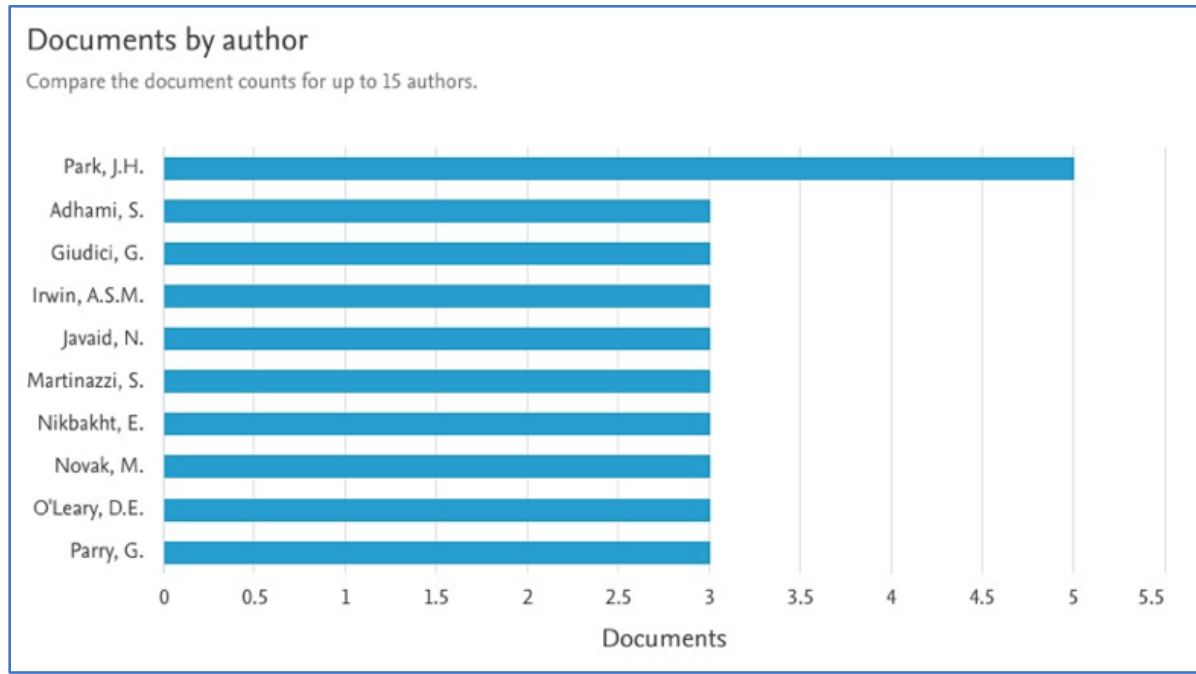

Figure 2.12 - The Authors with Minimum of 3 Articles (Third Search)

\section{OVERVIEW OF BLOCKCHAIN ARTICLES}

\section{Number of publications by year}

The initial search on the keyword of "blockchain" gave a total of 18,567 documents resulting in the SCOPUS database on 13 March 2021. This number increases every day since authors are writing new articles on the subject of the search topic of blockchain. The most significant number was written in 2020 with 7,393 written documents compared with 5,899 documents in $2019,2,959$ documents in 2018,810 documents in 2017 , and reducing sharply to 180 documents in 2016, less than half in 2015 (i.e., 39 documents).

After the refined search, we get 506 documents showing the same increasing trend in publications every year. We got this result as identified in the SCOPUS database for all the years. The majority of the documents had been written in 2020 (with 237 articles), which is more than doubled what had been written in 2019 (with 105 articles). In the first quarter of this year, 2021, authors had written 58, and although it is still early to see the final count for the year, the trend is that the number of written articles increases every year, as shown in Figure 2.7 earlier.

\section{Number of Publications by Sources and Network Map}

\section{Publication by Sources}

When the minimum number of documents of a source is set to three as a minimum, out of the 177 sources, we got 42 source that meets the threshold. We selected the minimum number of five documents of a source as a threshold, and we got 24 sources that meet this threshold out of the 177 sources. In Table 3.1, we list the first 15 entries sorted on the highest number of average citations. From this table, we can observe that although Financial Innovation had only 7 publications, those publications had 425 citations, with an average citation equal to 60.7 . This is the highest number of average citations. This observation means that the publications from Financial Innovation are high-quality documents cited more often by researchers. We can evaluate from Table 3.1 that although some sources had produced more documents than Financial Innovation (and accordingly had more citations), the quality of those documents is 
not linked with the number of publications. For example, we can see that Sustainability (Switzerland) had published 88 documents with massive 623 citations. Still, the average citation for Sustainability (Switzerland) is only 7.1, and that does not qualify this source to be in the first ten leading positions.

Table 3.1 - Top 10 Sources Based on Highest Average Citations

\begin{tabular}{|c|c|c|c|c|}
\hline Source & Documents & Citations & $\begin{array}{l}\text { Average } \\
\text { Citation }\end{array}$ & $\begin{array}{c}\text { Total } \\
\text { Link } \\
\text { Strength } \\
\end{array}$ \\
\hline Financial Innovation & 7 & 425 & 60.7 & 209 \\
\hline Intelligent Systems In Accounting, Finance And Management & 6 & 265 & 44.2 & 313 \\
\hline Decision Support Systems & 5 & 153 & 30.6 & 165 \\
\hline Strategic Change & 14 & 387 & 27.6 & 656 \\
\hline Sustainable Cities And Society & 10 & 272 & 27.2 & 411 \\
\hline International Journal Of Production Economics & 9 & 195 & 21.7 & 689 \\
\hline Electricity Journal & 4 & 57 & 14.3 & 109 \\
\hline International Journal Of Accounting Information Systems & 6 & 64 & 10.7 & 218 \\
\hline Small Business Economics & 8 & 78 & 9.8 & 587 \\
\hline $\begin{array}{l}\text { Journal Of Open Innovation: Technology, Market, And } \\
\text { Complexity }\end{array}$ & 6 & 49 & 8.2 & 386 \\
\hline Journal Of Legal, Ethical And Regulatory Issues & 5 & 36 & 7.2 & 88 \\
\hline Sustainability (Switzerland) & 88 & 623 & 7.1 & 3464 \\
\hline Energy Research And Social Science & 5 & 32 & 6.4 & 179 \\
\hline International Journal Of Digital Accounting Research & 5 & 29 & 5.8 & 338 \\
\hline Journal Of Industrial And Business Economics & 3 & 17 & 5.7 & 147 \\
\hline
\end{tabular}

From Figure 3.1, we can see that Sustainability (Switzerland) had a more extensive circle size showing many publications. In contrast, Financial Innovation had a smaller circle showing fewer publications, but as discussed earlier, the number of publications is not an indicator of quality. The reader can see this observation from the network of Financial Innovation in Figure 3.2. As we stated earlier, Table 3.1 shows that the publications from Financial Innovation are high-quality documents cited more often by researchers (average citation of 60.7 is the highest in Table 3.1).

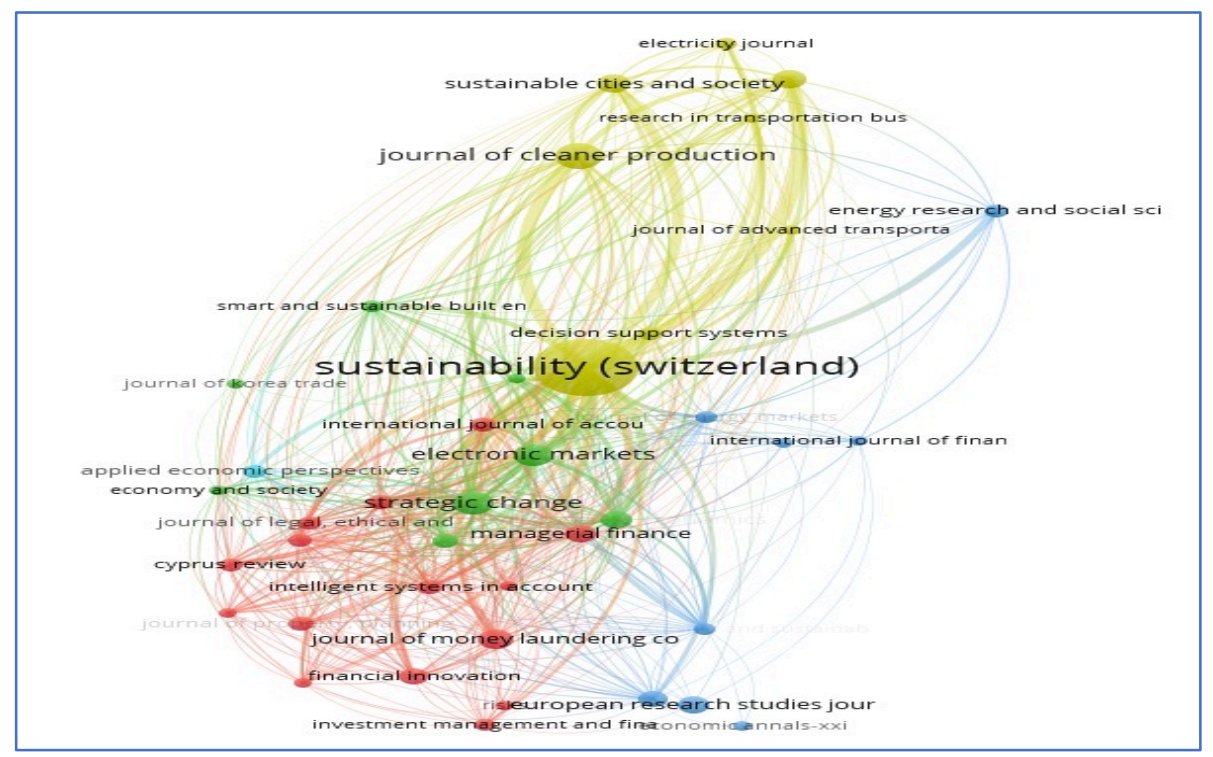

Figure 3.1 - The Publication Sources \& Networks 


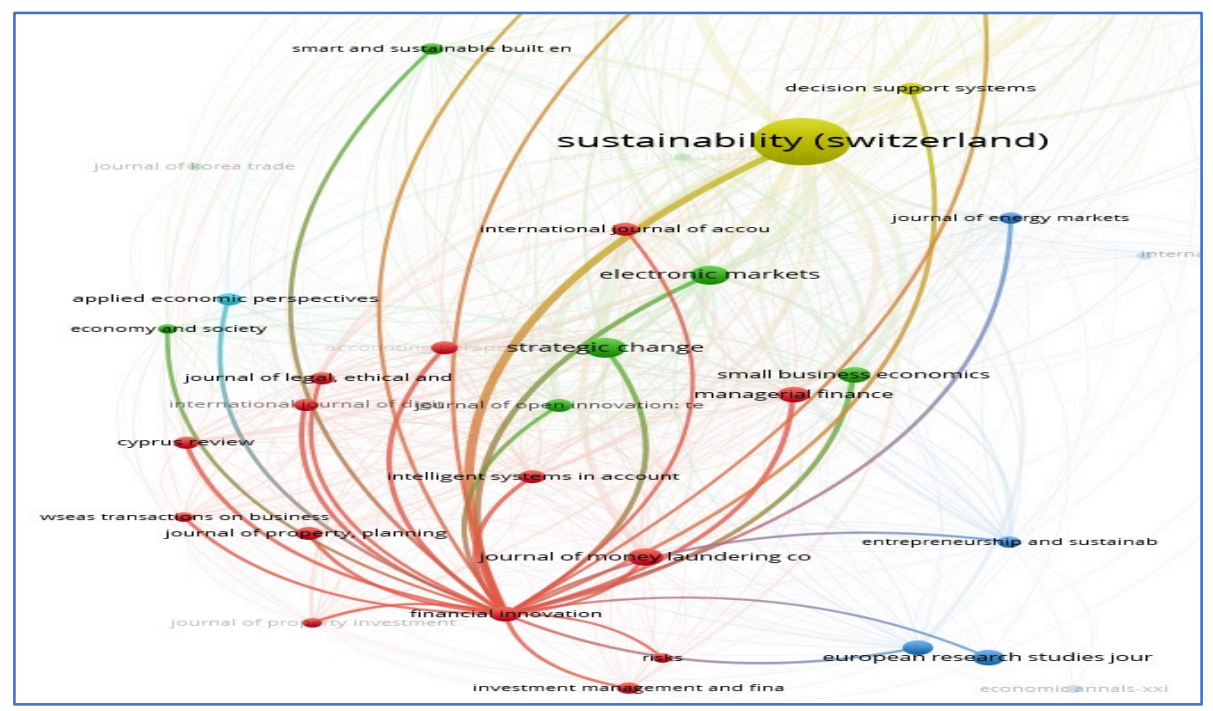

Figure 3.2 - Financial Innovation Network

\section{Network Map}

The bibliographic coupling technique assesses the occurrence of a standard reference to a document in the bibliographies of two or more publications; therefore, it lends insights into the current and prospective research boundaries of a particular subject matter (Tandon et al., 2021).

Using Bibliographic coupling with authors as units of analysis and a minimum number of 3 documents by an author, we get 18 out of 1278 authors meeting the thresholds. However, if we reduce the minimum documents of an author to 2, we get 98 out of the 1278 meeting the thresholds. We choose to use 3 documents as a threshold.

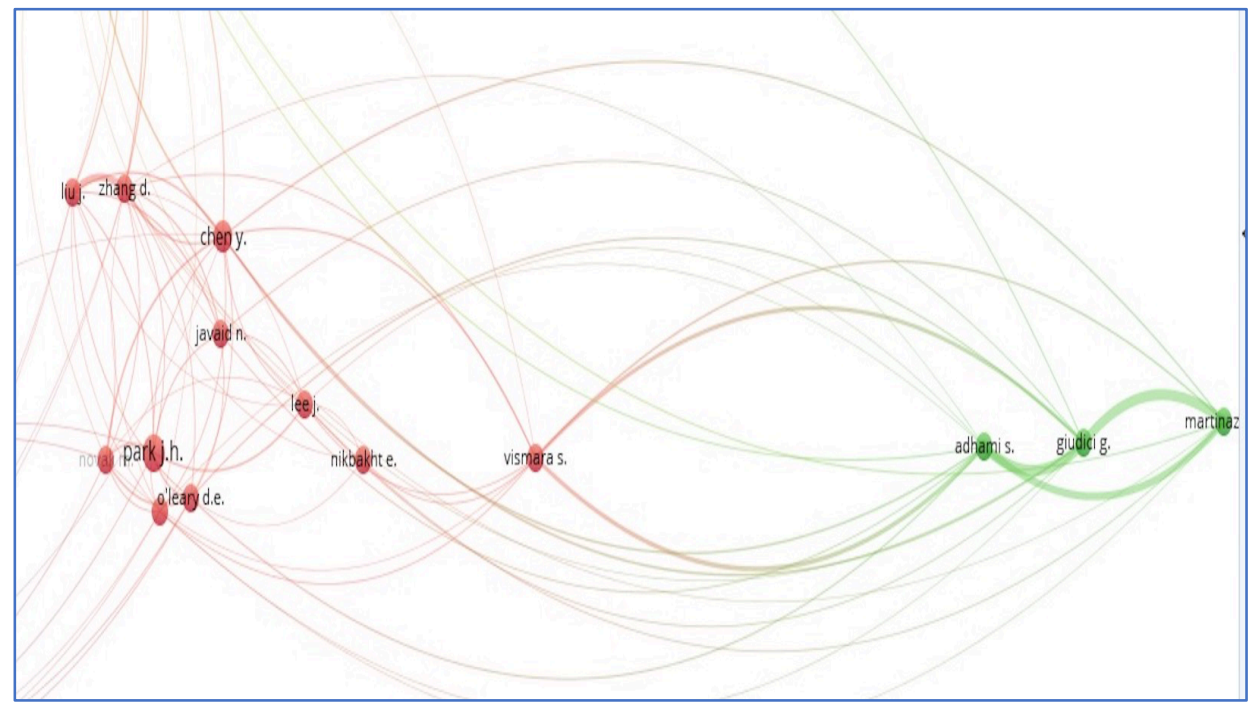

Figure 3.3 - Authors Network and Clusters

\section{Citation Map Based on Countries}

This part presents the countries that were involved in blockchain research as it highlights the author's country that recorded in the publications (Firdaus et al, 2019). Citation analysis, in general, assesses and evaluates the level of acceptance of a publication via a quantified assessment of its reference by other published reports (Tandon et al., 2021). This analysis assists in understanding the influence and popularity of individual documents and the 
collaborative network of citations (Tandon et al., 2021). The citation map uses a co-citation mapping technique to visualize how articles are co-cited and cited reciprocally over time (Fetscherin \& Heinrich, 2015). For the required mapping, we used a threshold of five documents as a minimum publication for a country (of the 79 countries) to qualify to enter the network map, and 36 countries had met this threshold. Those 36 in the network are not all connected, and the most extensive set of related items consisted of 34 countries.

The network map in Figure 3.4 shows that citations from the USA are connected with all the countries in the list except Lithuania, Cyprus, and Ukraine. In contrast, Lithuania is connected to Italy and Canada, while Cyprus is connected to Netherlands, UK, Australia, and Germany. Ukraine is shown to have connections only with UK and Germany.

From Tables 3.2 and 3.3, we can see that the USA is leading in citations with 1014, seconded by the UK with 709 citations. China had 640 citations, while Germany and South Korea had 395 and 297 citations, respectively.

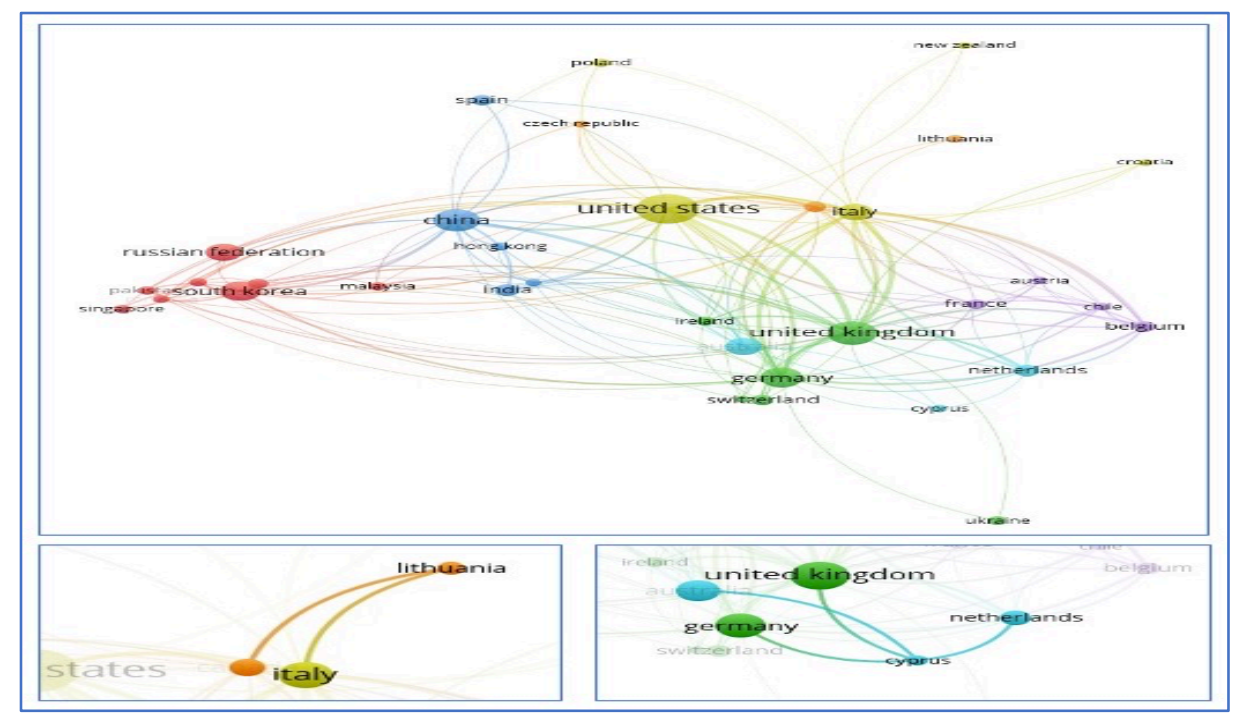

Figure 3.4 - Countries Network

Table 3.2 - Highest Countries Production (Sorted Citations)

\begin{tabular}{|c|c|c|c|}
\hline Country & Documents & Citations & $\begin{array}{c}\text { Total Link } \\
\text { Strength }\end{array}$ \\
\hline United States & 92 & 1014 & 145 \\
\hline United Kingdom & 59 & 709 & 144 \\
\hline China & 50 & 640 & 77 \\
\hline Germany & 42 & 395 & 106 \\
\hline South Korea & 40 & 297 & 51 \\
\hline Australia & 31 & 279 & 30 \\
\hline Italy & 28 & 247 & 119 \\
\hline Canada & 12 & 222 & 56 \\
\hline Hong Kong & 7 & 204 & 10 \\
\hline France & 10 & 130 & 36 \\
\hline Romania & 6 & 117 & 20 \\
\hline India & 15 & 108 & 23 \\
\hline Netherlands & 15 & 107 & 39 \\
\hline Belgium & 12 & 97 & 58 \\
\hline Poland & 8 & 89 & 4 \\
\hline \multicolumn{2}{|r|}{}
\end{tabular}


Table 3.3 - Highest Countries Production (Sorted Total Link Strength)

\begin{tabular}{|l|c|c|c|}
\hline \multicolumn{1}{|c|}{ Country } & Documents & Citations & $\begin{array}{c}\text { Total Link } \\
\text { Strength }\end{array}$ \\
\hline United States & 92 & 1014 & 145 \\
\hline United Kingdom & 59 & 709 & 144 \\
\hline Italy & 28 & 247 & 119 \\
\hline Germany & 42 & 395 & 106 \\
\hline China & 50 & 640 & 77 \\
\hline Belgium & 12 & 97 & 58 \\
\hline Canada & 12 & 222 & 56 \\
\hline South Korea & 40 & 297 & 51 \\
\hline Netherlands & 15 & 107 & 39 \\
\hline France & 10 & 130 & 36 \\
\hline Chile & 6 & 4 & 34 \\
\hline Australia & 31 & 279 & 30 \\
\hline India & 15 & 108 & 23 \\
\hline Ireland & 9 & 77 & 20 \\
\hline Romania & 6 & 117 & 20 \\
\hline
\end{tabular}

We conclude from Tables 3.2 and 3.3 that although Germany and South Korea had approximately a similar number of publications (with 42 and 40 documents), the citations to Germany's publications were 395 citations compared with South Korea's 297 citations. This observation indicates that Germany's publications were more influential in subsequent written articles than South Korea's publications.

\section{Number of documents by country}

Compared with Figure 2.8, the filtered research changed the percentage of documents by country where the USA is leading with 92 published articles, as depicted in Figure 3.6 below. The UK has 59 published articles; China has 50 published articles; Germany has 42 published articles near South Korea 40 published articles. Both Australia and Russian Federation have 31 published articles, followed by Italy with 28 published articles. India and Netherlands both have 15 published articles.

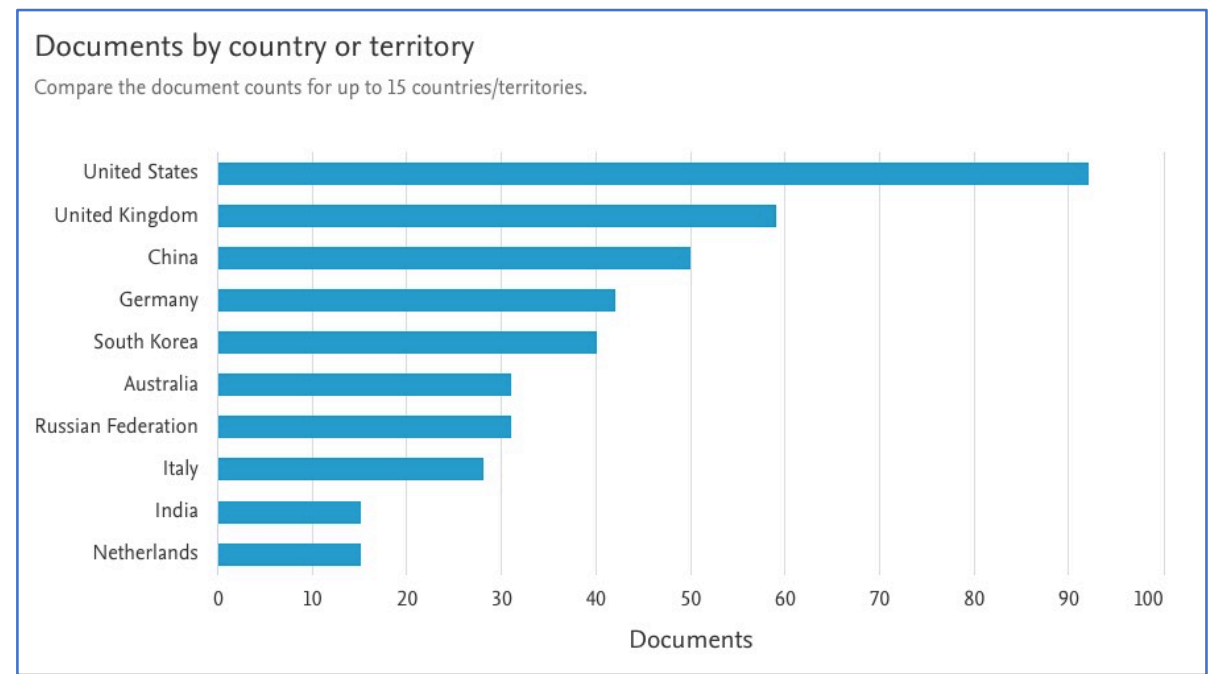

Figure 3.6 - Highest Publishing Countries

Analysis of citation per country (without selecting the option to ignore documents co-authored by a large number of countries) with a minimum of 5 documents by a country, 36 out of the 79 countries met the threshold. Table 3.4 shows that the USA has the highest number of publications on the blockchain, with 92 articles producing 1014 citations. The UK follows this 
with 59 publications producing 709 citations. China came in the third position with 50 publications producing 640 citations, Germany comes in the fourth position with 42 publications producing 395 citations, followed closely with South Korea with 40 publications producing 297 citations.

Table 3.4 - Countries Produced Documents' Citations

\begin{tabular}{|c|c|c|c|c|c|}
\hline Country & Documents & $\begin{array}{c}\text { Percentage } \\
\mathbf{( \% )}\end{array}$ & Citations & $\begin{array}{c}\text { Average } \\
\text { Citation } \\
\text { Per } \\
\text { Document }\end{array}$ & $\begin{array}{c}\text { Total } \\
\text { Link } \\
\text { Strength }\end{array}$ \\
\hline United States & 92 & 15.3 & 1014 & 11.0 & 145 \\
\hline United Kingdom & 59 & 9.8 & 709 & 12.0 & 144 \\
\hline China & 50 & 8.3 & 640 & 12.8 & 77 \\
\hline Germany & 42 & 7.0 & 395 & 9.4 & 106 \\
\hline South Korea & 40 & 6.7 & 297 & 7.4 & 51 \\
\hline Australia & 31 & 5.2 & 279 & 9 & 30 \\
\hline Russian Federation & 31 & 5.2 & 77 & 2.5 & 5 \\
\hline Italy & 28 & 4.7 & 247 & 8.8 & 119 \\
\hline India & 15 & 2.5 & 108 & 7.2 & 23 \\
\hline Netherlands & 15 & 2.5 & 107 & 7.1 & 39 \\
\hline Belgium & 12 & 2.0 & 97 & 8.1 & 58 \\
\hline Canada & 12 & 2.0 & 222 & 18.5 & 56 \\
\hline Spain & 12 & 2.0 & 32 & 2.7 & 7 \\
\hline Switzerland & 12 & 2.0 & 83 & 6.9 & 10 \\
\hline France & 10 & 1.7 & 130 & 13.0 & 36 \\
\hline
\end{tabular}

The analysis of Table 3.5 shows that Hong Kong, which published only seven documents produced 204 citations, had the highest average citation per document with a score of 29.1. In the second and third positions came Romania (19.5) and Canada (18.5) respectively. France (13.0) and China (12.8) came in the fourth and fifth positions, respectively.

Table 3.5 - Countries Average Citation Per Document

\begin{tabular}{|l|c|c|c|c|c|}
\hline \multicolumn{1}{|c|}{ Country } & Documents & $\begin{array}{c}\text { Percentage } \\
\mathbf{( \% )}\end{array}$ & Citations & $\begin{array}{c}\text { Average } \\
\text { Citation } \\
\text { Per } \\
\text { Document }\end{array}$ & $\begin{array}{c}\text { Total } \\
\text { Link } \\
\text { Strength }\end{array}$ \\
\hline Hong Kong & 7 & 1.2 & 204 & 29.1 & 10 \\
\hline Romania & 6 & 1.0 & 117 & 19.5 & 20 \\
\hline Canada & 12 & 2.0 & 222 & 18.5 & 56 \\
\hline France & 10 & 1.7 & 130 & 13.0 & 36 \\
\hline China & 50 & 8.3 & 640 & 12.8 & 77 \\
\hline United Kingdom & 59 & 9.8 & 709 & 12.0 & 144 \\
\hline Poland & 8 & 1.3 & 89 & 11.1 & 4 \\
\hline United States & 92 & 15.3 & 1014 & 11.0 & 145 \\
\hline Germany & 42 & 7.0 & 395 & 9.4 & 106 \\
\hline Singapore & 8 & 1.3 & 75 & 9.4 & 6 \\
\hline Australia & 31 & 5.2 & 279 & 9 & 30 \\
\hline Saudi Arabia & 7 & 1.2 & 63 & 9.0 & 16 \\
\hline Italy & 28 & 4.7 & 247 & 8.8 & 119 \\
\hline Ireland & 9 & 1.5 & 77 & 8.6 & 20 \\
\hline Pakistan & 8 & 1.3 & 66 & 8.3 & 15 \\
\hline
\end{tabular}

Although France had produced only ten documents, it had 130 citations and an average citation of 13. In comparison, China produced 50 documents and accordingly had 640 citations and an average citation of 12.8. The higher number of average citations makes France publications of higher impact in the field. 
We find that the average citation per document is the caliber we can use to judge high-quality influential publications; therefore, although the USA had the highest number of publications (92 documents) on the quality of the publication, it comes in the $8^{\text {th }}$ position.

\section{Title Map}

We analyzed the title map using two methods to see the differences between each method's results to select the most applicable method forward once we run the data in the analysis software. Firstly, we used a method called 'binary counting', which means that only the presence or the absence of a term in a document matter. Secondly, we used a method called 'full counting', which means the software counts all occurrences of a term in a document.

We got the following results:

1 - With five occurrences of a term, 31 terms out of 1332 terms met the threshold.

2 - With ten occurrences of a term, only 10 terms out of 1332 terms met the threshold.

The title of 'blockchain' has a network with all of the 31 terms or the 10 terms depending on the number of a term occurrence (10 or 5). Table 3.6 results from the 10 terms occurrences, which is the selected number for the continuation of the analysis and is depicted graphically in Figure 3.7 below. Figure 3.8 below show the result of the 5 terms minimum occurrences.

Table 3.6 - Sorted Occurrences and Relevance Score of Terms

\begin{tabular}{|c|c|c|c|c|c|c|c|c|}
\hline Term & Occurrence & \begin{tabular}{|c} 
Relevance \\
score
\end{tabular} & Term & Occurrence & $\begin{array}{c}\text { Relevance } \\
\text { score }\end{array}$ & Term & Occurrence & $\begin{array}{c}\text { Relevance } \\
\text { score }\end{array}$ \\
\hline application & 28 & 0.5467 & blockchain & 177 & 1.2425 & initial coin offering & 17 & 1.5612 \\
\hline bitcoin & 16 & 0.6856 & blockchain technology & 61 & 1.509 & blockchain technology & 61 & 1.509 \\
\hline blockchain & 177 & 1.2425 & technology & 35 & 0.2352 & implication & 15 & 1.5087 \\
\hline blockchain technology & 61 & 1.509 & application & 28 & 0.5467 & blockchain & 177 & 1.2425 \\
\hline cryptocurrency & 27 & 1.1135 & cryptocurrency & 27 & 1.1135 & cryptocurrency & 27 & 1.1135 \\
\hline impact & 16 & 0.8747 & study & 24 & 0.723 & impact & 16 & 0.8747 \\
\hline implication & 15 & 1.5087 & initial coin offering & 17 & 1.5612 & study & 24 & 0.723 \\
\hline initial coin offering & 17 & 1.5612 & bitcoin & 16 & 0.6856 & bitcoin & 16 & 0.6856 \\
\hline study & 24 & 0.723 & impact & 16 & 0.8747 & application & 28 & 0.5467 \\
\hline technology & 35 & 0.2352 & implication & 15 & 1.5087 & technology & 35 & 0.2352 \\
\hline
\end{tabular}

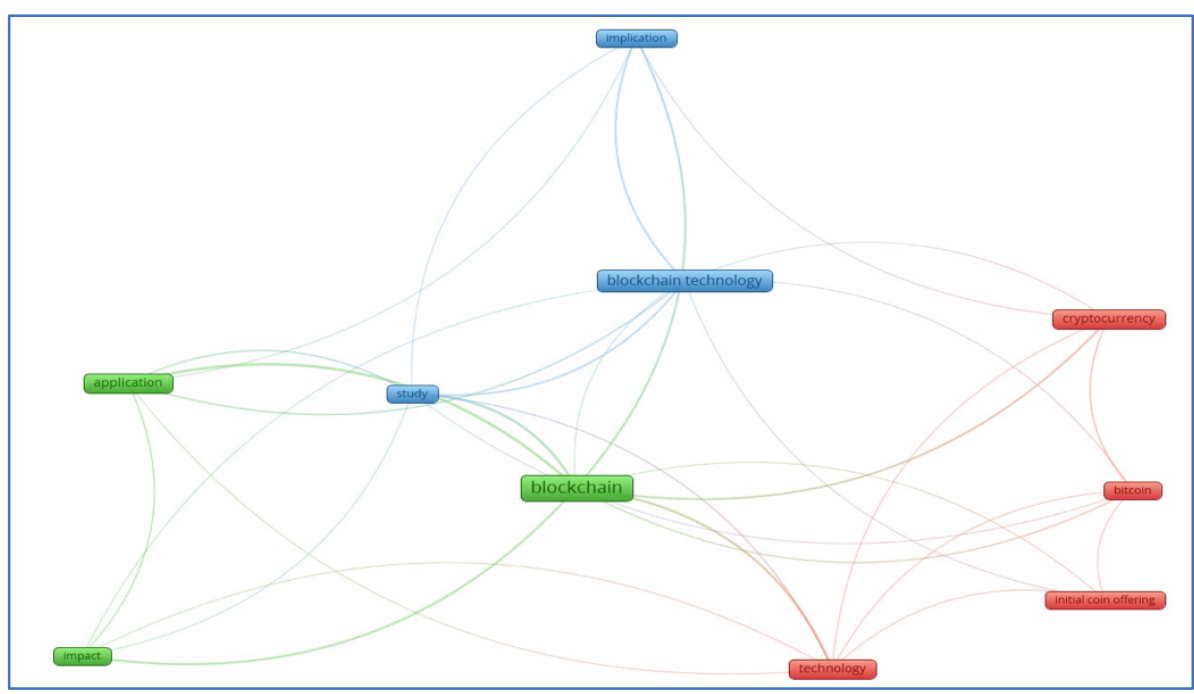

Figure 3.7 - Main Keywords Occurrences Network 


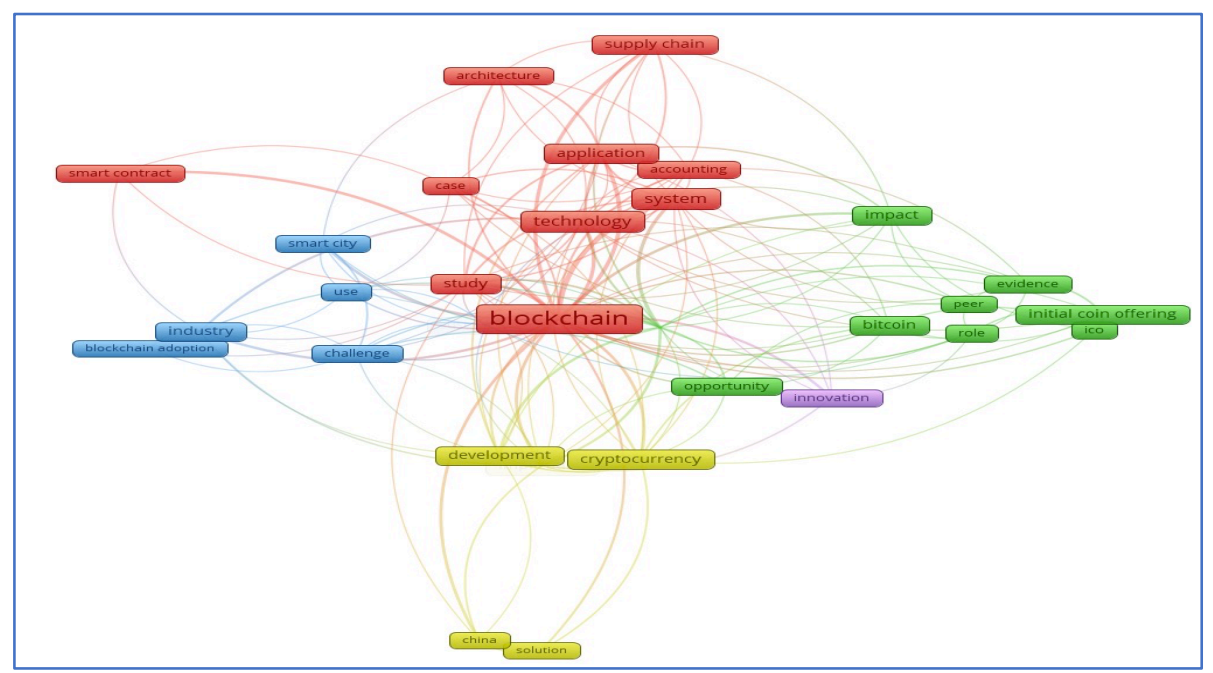

Figure 3.8 - Results of Terms Occurrences (Minimum of 5 Terms)

\begin{abstract}
Map
In the Abstract Map, we got a large set of keywords in the abstract of all the articles we searched for in the Scopus database. Initially, we will be examining all the keywords using two methods. The first method is called Binary Counting, and the second is called Full Counting. Previously in the title map, the results of both methods were equivalent. Still, in the trials used for the Abstract Map analysis using the same data set, the results of the two methods were different. Although we are going with the result of the second method (i.e., Full Counting), we are listing the findings of the first method for the reader's knowledge. We will do another abstract map using selected keywords related to blockchain directly, and we will be using the full counting method in the analysis.
\end{abstract}

\title{
First Run Using All Keywords (Binary Counting Method)
}

Binary counting means that only the presence or the absence of a term in a document matter. The number of occurrences of a term in a document is not taken into account. Using ten as the minimum number of term occurrences, 246 of the 10,135 terms met the threshold. A relevance score was calculated for each of the 246 terms. Based on this score, the most relevant terms were selected. The software grouped the 246 items into 5 clusters with 24,129 links with a total link strength of 104,141 .

In the analysis of the words used in the abstracts of the articles, the term 'blockchain' occurred 293, was in cluster 2, had 245 links, and total link strength of 5,863. The word 'blockchain technology' occurred 221, was also in cluster 2, had similar 245 links (as the previous word) with total link strength of 4,390. The term 'ICO' occurred 25 times but has the highest relevance score of 11.94, while the word 'Initial Coin Offering,' which meant the same thing as 'ICO,' has occurred 29 times but had a lower relevance score 9.97. Interestingly, 'cryptocurrency' occurred 70 times, was in cluster 1, had 234 links with total link strength of 1,359, but had 1.13 as relevance score. The term 'smart contract' occurred 60 times, was in cluster 2, had 235 links and total link strength of 1,315, and had a 0.61 relevance score. Figure 3.9 shows the graphical representation. In Figure 3.10, below are the network maps for four of the discussed terms. 


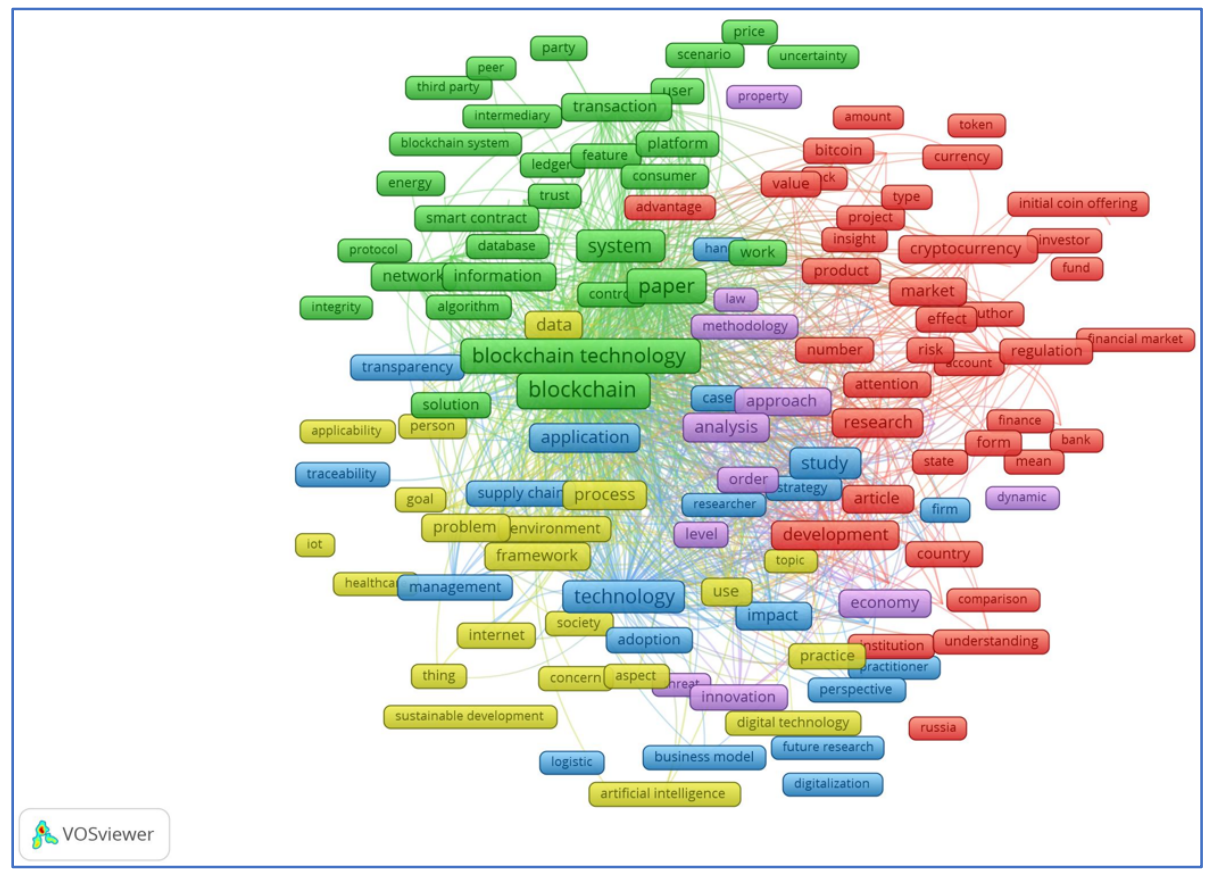

Figure 3.9 - Box Representation

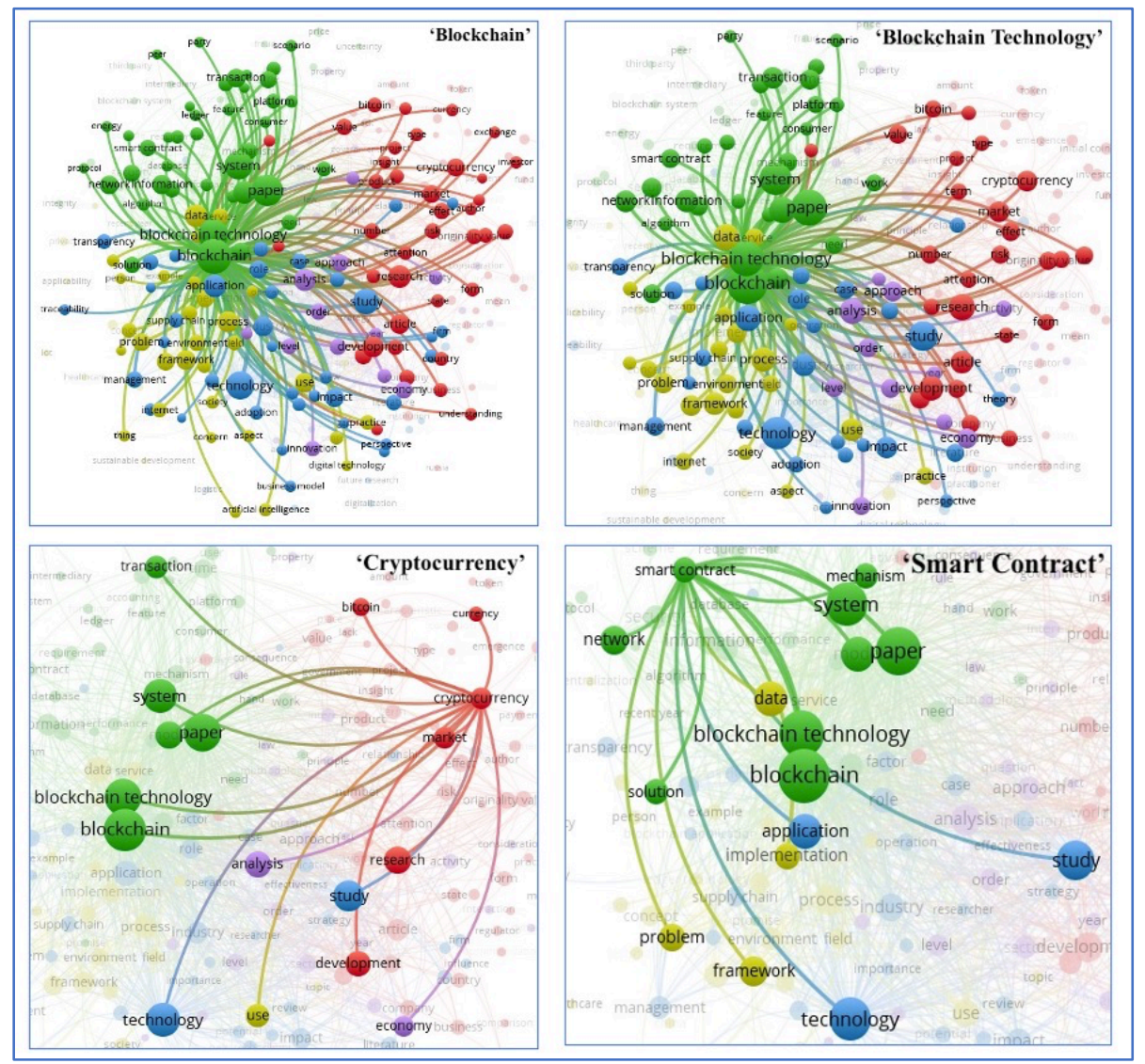

Figure 3.10 - Network Map for Each Term Discussed (First Run) 
Table 3.7 - The Highest 15 Terms in Occurrences and Highest in Relevance Score

\begin{tabular}{|l|c|l|l|c|l|}
\hline Term & Occurrences & $\begin{array}{l}\text { Relevance } \\
\text { Score }\end{array}$ & Term & Occurrences & $\begin{array}{l}\text { Relevance } \\
\text { Score }\end{array}$ \\
\hline blockchain & 293 & 0.0951 & ico & 25 & 11.9425 \\
paper & 224 & 0.0894 & initial coin offering & 29 & 9.9794 \\
blockchain technology & 221 & 0.1071 & success & 18 & 3.872 \\
technology & 188 & 0.1495 & research limitations & 13 & 3.8494 \\
& & & implication & & \\
system & 182 & 0.1662 & financial market & 10 & 3.8262 \\
study & 157 & 0.1509 & investor & 34 & 3.5395 \\
research & 119 & 0.1396 & fund & 15 & 3.4984 \\
application & 116 & 0.1439 & period & 13 & 3.3517 \\
data & 114 & 0.1838 & third party & 11 & 3.1765 \\
model & 114 & 0.1633 & token & 22 & 3.0761 \\
analysis & 110 & 0.0916 & money & 21 & 2.7399 \\
development & 100 & 0.2888 & iot & 15 & 2.6821 \\
process & 97 & 0.0992 & russia & 12 & 2.5691 \\
use & 88 & 0.206 & finance & 18 & 2.5446 \\
industry & 87 & 0.0931 & big data & 23 & 2.5278 \\
\hline
\end{tabular}

\section{Second Run using all keywords (Full Counting Method)}

In this run, we are using the full counting method to count all term occurrences in a document. With a minimum of term occurrences equal to 10 , only 320 out of 10,135 met the threshold. For each of the 320 terms, the software's relevance score will be calculated and based on the score; the most relevant terms will be shown.

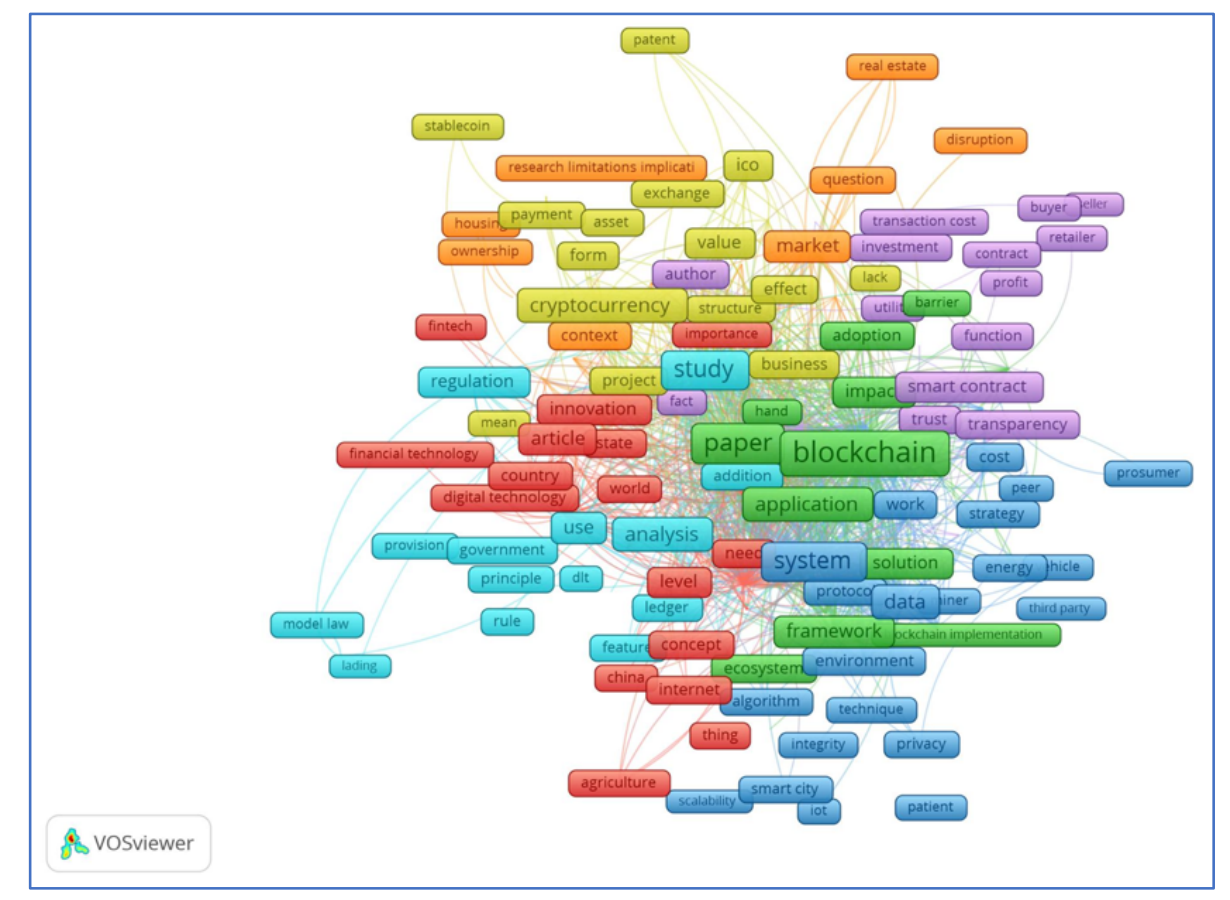

Figure 3.11 - Abstract Network Labeled in Frames (Boxes) 


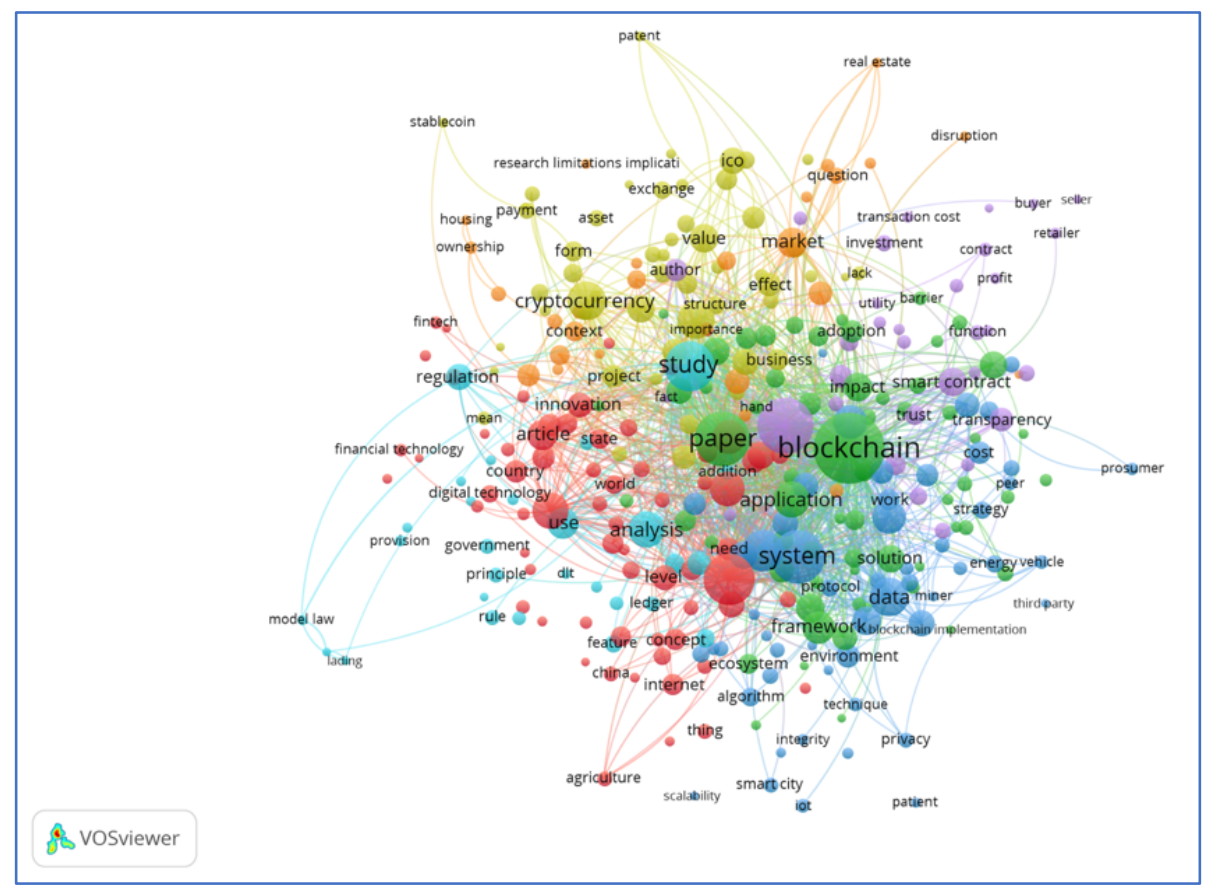

Figure 3.12 - Abstract Network Labeled in Circles

Table 3.8 - The Highest 15 terms with 'Occurrences' and Highest with 'Relevance Score' Sorted Results (Second Run)

\begin{tabular}{|l|c|c|l|c|c|}
\hline Term & Occurrences & $\begin{array}{c}\text { Relevance } \\
\text { Score }\end{array}$ & Term & Occurrences & $\begin{array}{c}\text { Relevance } \\
\text { Score }\end{array}$ \\
\hline blockchain & 619 & 0.1243 & model law & 13 & 16.1942 \\
blockchain technology & 396 & 0.0831 & electronic bill & 11 & 15.9785 \\
paper & 371 & 0.0661 & lading & 12 & 14.6374 \\
system & 355 & 0.1092 & housing & 15 & 10.2533 \\
technology & 327 & 0.1165 & ownership & 19 & 7.3398 \\
study & 311 & 0.1728 & stablecoin & 14 & 5.1118 \\
model & 214 & 0.1529 & provision & 18 & 4.9488 \\
data & 191 & 0.2996 & initial coin offering & 37 & 3.9088 \\
cryptocurrency & 182 & 0.8059 & smes & 11 & 3.5576 \\
research & 178 & 0.1351 & real estate & 13 & 3.3383 \\
application & 161 & 0.1182 & difference & 14 & 3.3263 \\
analysis & 160 & 0.1291 & retailer & 17 & 3.2977 \\
development & 159 & 0.32 & ico & 83 & 3.0752 \\
process & 151 & 0.082 & property & 29 & 3.0024 \\
transaction & 145 & 0.3241 & sample & 13 & 2.9939 \\
\hline
\end{tabular}

Observing the same terms considered earlier with the binary method, we see a more extensive occurrence of the term 'blockchain' of 619 with 318 links and total link strength of 20,874. In comparison, the term 'blockchain technology' came in the second position of 396 occurrences with 316 links and total link strength of 12,762. The terms 'ICO' and 'Initial Coin Offering' were in the same cluster and came in the $39^{\text {th }}$ and $127^{\text {th }}$ position with scores of 83 and 37 respectively, with 165 links and total link strength of 2346 for 'ICO', and 183 links and total link strength of 980 for 'Initial Coin Offering'. The term 'cryptocurrency' came in the $9^{\text {th }}$ position with 182 occurrences with 281 links and total link strength of 5,490. The term 'smart contract' came in the $24^{\text {th }}$ position with a score of 104 occurrences, 289 links, and total link strength of 3,644 .

The highest relevancy score is 16.19 for the term 'model law' with 13 occurrences and comes in the second position is the term 'electronic bill' with 15.97 and 11 occurrences. The terms 
'Initial Coin Offering' and 'ICO' came in the $8^{\text {th }}$ and $13^{\text {th }}$ positions with relevance scores of 3.9 and 3.07. The term' cryptocurrency' came in the $108^{\text {th }}$ position with a 0.80 relevance score, while the term 'smart contract' came in the $169^{\text {th }}$ position with a 0.48 relevance score.
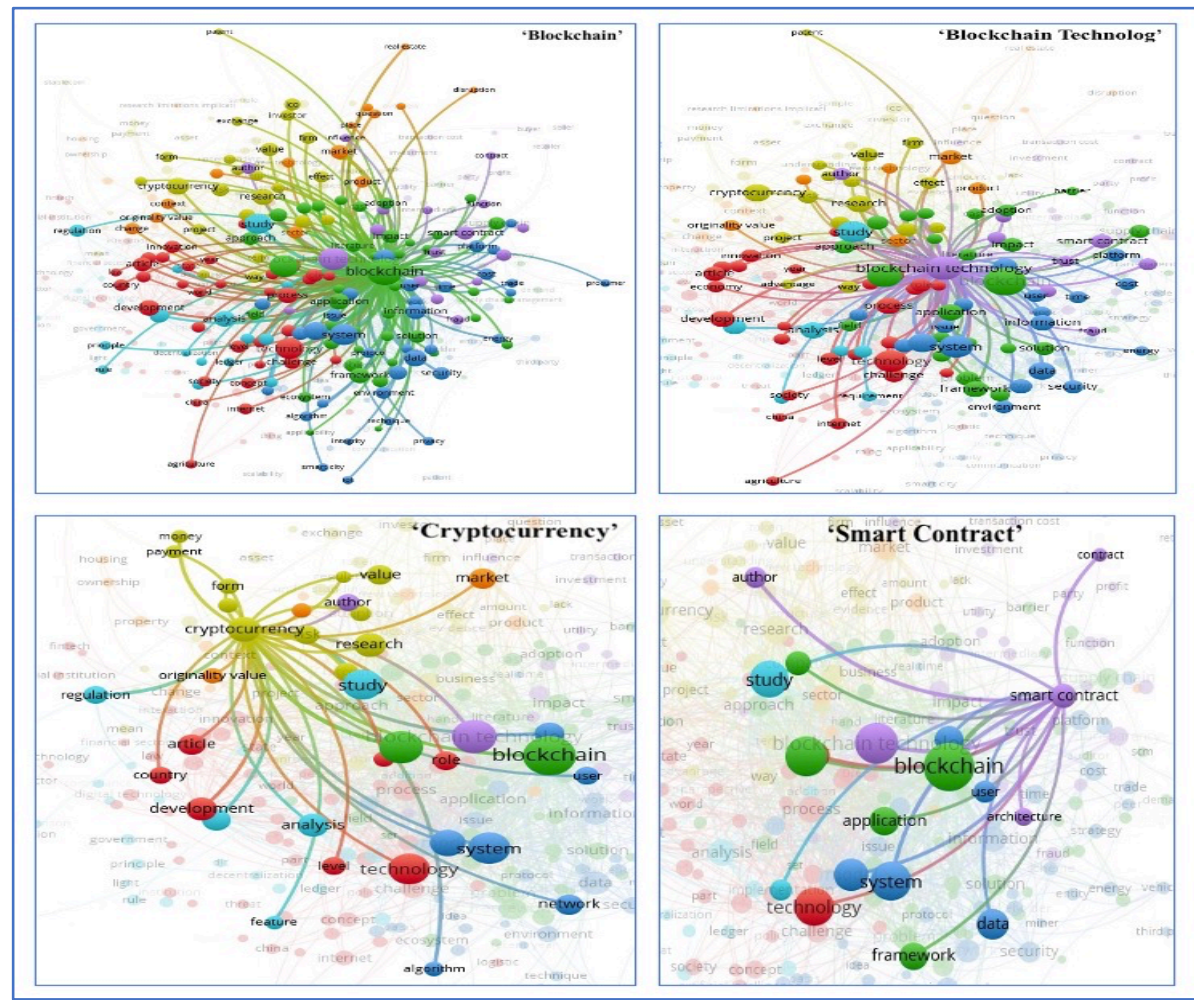

Figure 3.13 - Occurrences for the Four Terms (Second Run)

\section{Third Run (Selected Keywords)}

In this run, using a minimum number of 10 occurrences of a term (as per the software default) and 320 out of 10,135 terms met the threshold. We selected 85 terms that we believe directly connect to the blockchain (listed in Table 3.9), and used them in the analysis software.

Table 3.9 - The Selected Terms Used in Abstracts Related to Blockchain

\begin{tabular}{|c|c|c|c|c|}
\hline advantage & capital & energy & ledger & security \\
\hline algorithm & circular economy & finance & ledger technology & smart contract \\
\hline application & combination & financial institution & logistic & stablecoin \\
\hline artificial intelligence & compliance & financial market & machine learning & supply chain \\
\hline asset & contract & financial sector & mining & supply chain management \\
\hline bank & country & fintech & money & sustainability \\
\hline banking sector & cryptocurrency & fraud & new technology & token \\
\hline barrier & $\begin{array}{l}\text { cryptocurrency } \\
\text { market }\end{array}$ & fund & ownership & traceability \\
\hline big data & currency & future research & payment & trade \\
\hline bitcoin & decentralization & healthcare & platform & transaction cost \\
\hline blockchain & digital economy & ico & practical implication & transparency \\
\hline blockchain application & digital technology & information asymmetry & privacy & uncertainty \\
\hline blockchain implementation & digital transformation & initial coin offering & real estate & virtual currency \\
\hline blockchain platform & digitalization & integration & real time & \\
\hline blockchain system & disruptive technology & integrity & regulation & \\
\hline blockchain technology & economy & intermediary & regulator & \\
\hline business model & effectiveness & investment & research & \\
\hline capability & efficiency & law & risk & \\
\hline
\end{tabular}




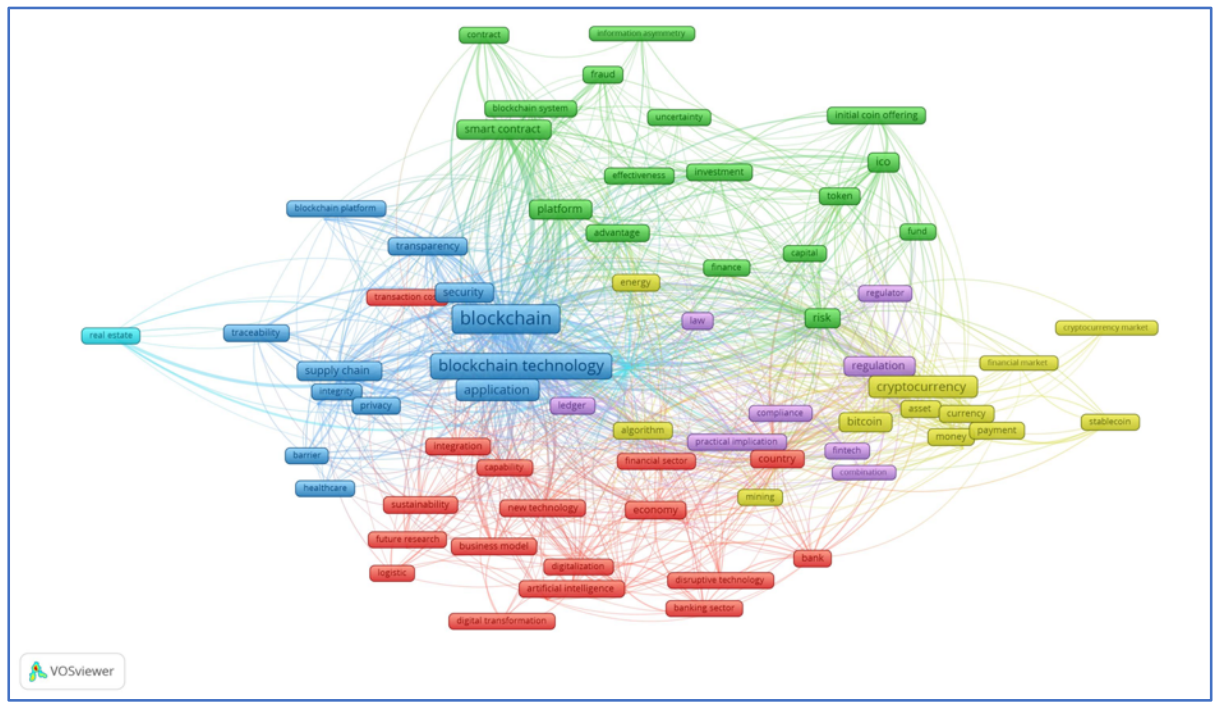

Figure 3.14 - Network Visualization (Frames) of Selected Keywords in Abstracts

The following two Tables had been generated with the analysis of the number of occurrences and relevance score. Table 3.10 shows the 15 highest occurrences of the selected terms, while Table 3.11 shows the 15 highest relevance scores of the selected terms.

Table 3.10 - The 15 Highest Occurrences of Selected Term (Third Run)

\begin{tabular}{|l|c|c|}
\hline \multicolumn{1}{|c|}{ Term } & Occurrences & Relevance Score \\
\hline blockchain & 619 & 0.304 \\
\hline blockchain technology & 396 & 0.252 \\
\hline cryptocurrency & 182 & 1.443 \\
\hline research & 178 & 0.0489 \\
\hline application & 161 & 0.2074 \\
\hline smart contract & 104 & 0.7769 \\
\hline supply chain & 95 & 0.8591 \\
\hline risk & 92 & 0.4746 \\
\hline security & 89 & 0.3464 \\
\hline ico & 83 & 2.2623 \\
\hline regulation & 83 & 1.5472 \\
\hline platform & 82 & 0.3392 \\
\hline bitcoin & 81 & 0.9257 \\
\hline transparency & 70 & 0.7074 \\
\hline country & 65 & 0.8242 \\
\hline
\end{tabular}

Table 3.11 - The 15 Highest Relevance Score of Selected Term (Third Run)

\begin{tabular}{|l|c|c|}
\hline \multicolumn{1}{|c|}{ Term } & Occurrences & Relevance Score \\
\hline stablecoin & 14 & 4.7662 \\
\hline cryptocurrency market & 11 & 3.3686 \\
\hline financial market & 11 & 2.9677 \\
\hline initial coin offering & 37 & 2.8502 \\
\hline banking sector & 15 & 2.5685 \\
\hline ico & 83 & 2.2623 \\
\hline bank & 36 & 2.2115 \\
\hline payment & 32 & 2.0984 \\
\hline money & 31 & 2.0427 \\
\hline virtual currency & 10 & 1.9746 \\
\hline financial institution & 18 & 1.949 \\
\hline currency & 47 & 1.9342 \\
\hline digital technology & 38 & 1.6144 \\
\hline asset & 33 & 1.5881 \\
\hline digitalization & 22 & 1.585 \\
\hline
\end{tabular}




\section{Analysis of Abstract Map}

Although the term 'blockchain' occurred 619 times in the articles data set we got, we had 84 links and a total link strength of 4,882; but its relevance score is only 0.304 . In comparison, the term 'stablecoin' occurred only 14 times (which puts it in the $74^{\text {th }}$ position, being close to the last place of 85), but it had the most substantial relevance score of 4.766 .

The term 'blockchain technology' occurred 396 occurrences, has 82 links, total link strength of 3,062, and the average publication per year is 2019.44. From the network visualization in Figure 3.14, we see the highest term occurrence is 'blockchain' followed by 'blockchain technology' closely followed by the term 'application', which has 81 links, and total link strength of 1,494 , occurred 161 .

\section{ANALYSIS OF AUTHORS}

\section{Document Number by Authors}

From Table 4.1, we can see that Adhami S. had only three documents published but had the highest number of citations (150) and highest average citation (50), followed closely by Giudici G. with the same number of documents but with fewer citations (149) and less average citation (49.7). We can also see from the same Table that Park J.H. had a higher number of 5 documents published but had fewer citations (47) and low average citation (9.4).

Table 4.1 - Authors with 3 Articles or More

\begin{tabular}{|c|c|c|c|c|}
\hline Author & Documents & Citations & $\begin{array}{c}\text { Average } \\
\text { Citation }\end{array}$ & $\begin{array}{c}\text { Total Link } \\
\text { Strength }\end{array}$ \\
\hline Adhami S. & 3 & 150 & 50.0 & 218 \\
\hline Giudici G. & 3 & 149 & 49.7 & 274 \\
\hline Martinazzi S. & 3 & 136 & 45.3 & 192 \\
\hline Li X. & 3 & 134 & 44.7 & 68 \\
\hline Parry G. & 3 & 97 & 32.3 & 18 \\
\hline O'leary D.E. & 3 & 82 & 27.3 & 31 \\
\hline Irwin A.S.M. & 3 & 49 & 16.3 & 78 \\
\hline Park J.H. & 5 & 47 & 9.4 & 29 \\
\hline Vismara S. & 3 & 44 & 14.7 & 59 \\
\hline Javaid N. & 3 & 40 & 13.3 & 20 \\
\hline Lee J. & 3 & 32 & 10.7 & 21 \\
\hline Chen Y. & 4 & 18 & 4.5 & 56 \\
\hline Novak M. & 3 & 18 & 6.0 & 30 \\
\hline Liu J. & 3 & 17 & 5.7 & 80 \\
\hline Turner A.B. & 3 & 11 & 3.7 & 77 \\
\hline Wang D. & 3 & 3 & 1.0 & 52 \\
\hline Nikbakht E. & 3 & 2 & 0.7 & 5 \\
\hline Zhang D. & 3 & 2 & 0.7 & 88 \\
\hline
\end{tabular}

\section{Authors network}

We used Co-authorship as a type of analysis with authors as a unit of analysis and three documents of an author as a minimum. Out of the 1,278 authors, 18 authors met the thresholds. The result can also be derived from Table 4.1 above and the network showing that the Adhami S., Giddici G., and Martinzazzi S. are all linked together, which we interpreted to cite each other or work together (out of the 18 authors). This is depicted in Figure 4.1 below. 


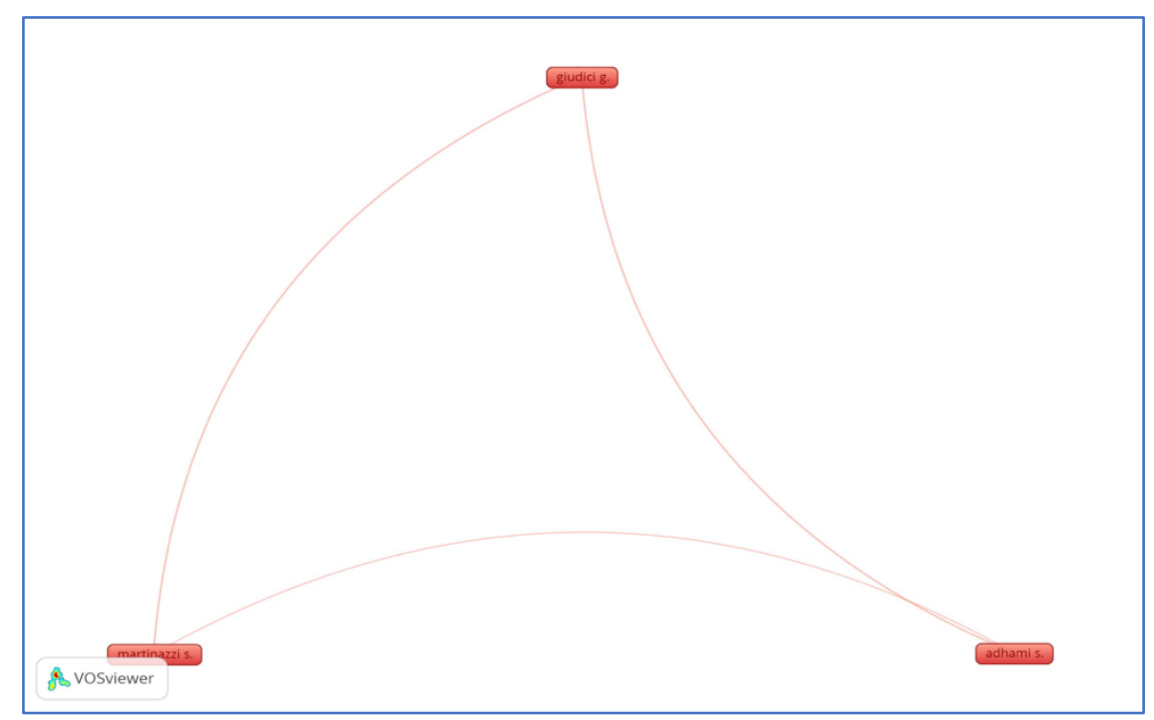

Figure 4.1 - Authors Working Together (Adhami, Giudici \& Martinazzi)

\section{Authors' Funding Organizations}

Although the data on funding organizations may not have been harmonized in Scopus data and therefore may not have a consistent format, we see from Figure 4.2 that the leading funding organization is the National Natural Science Foundation of China. The National Research Foundation of Korea came in the second position. The third position is shared by three organizations (Engineering and Physical Science Research Council, European Regional Development Fund, Ministry of Education). The fourth position is shared between Deutsche Forschungsgemeinschaft and Russian Foundation for Basic Research. The European Commission came in the fifth position.

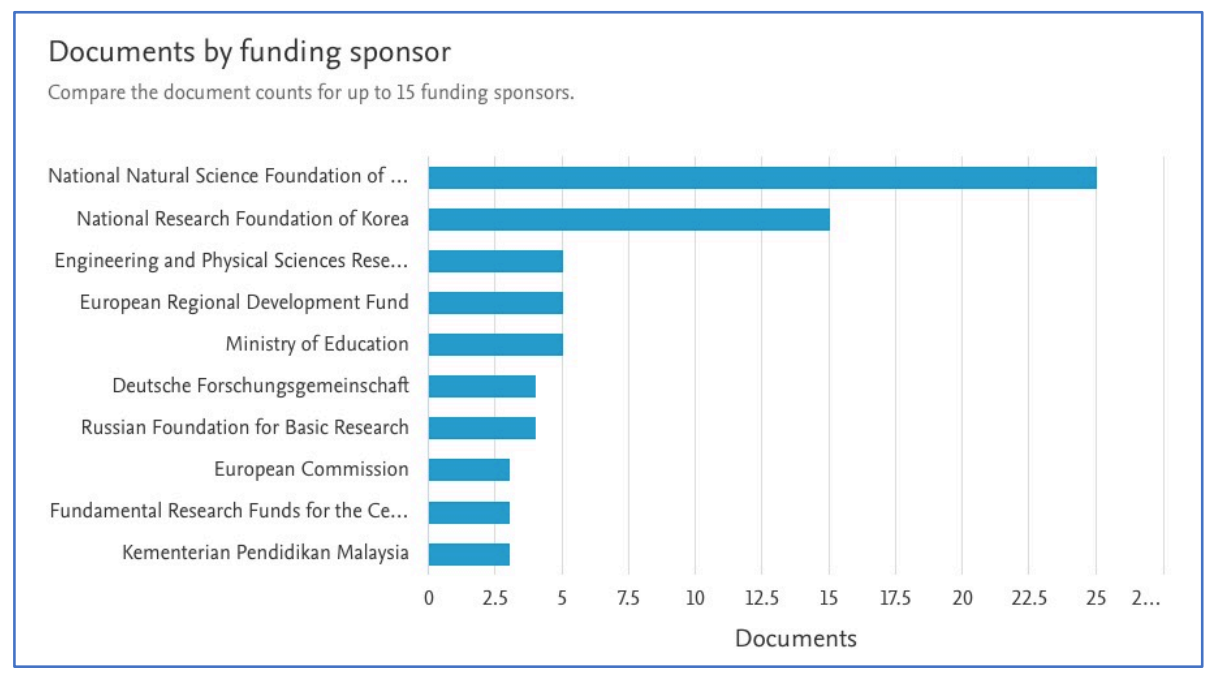

Figure 4.2 - The Funding Organizations

\section{Authors' Publication Organizations}

For researching and publishing organizations such as universities, we used co-authorship as a type of analysis. We used organizations as a unit of analysis (full counting) and three documents produced by the organization as a minimum number. We got five out of 1007 organizations that met the thresholds as depicted in Table 4.2 below.

Table 4.2 - The Average Citations for The Articles Produced by Organizations 


\begin{tabular}{|l|c|c|c|c|}
\hline \multicolumn{1}{|c|}{ Organization } & Documents & Citations & $\begin{array}{c}\text { Average } \\
\text { Citation }\end{array}$ & $\begin{array}{c}\text { Total Link } \\
\text { Strength }\end{array}$ \\
\hline University of Surrey, United Kingdom & 3 & 87 & 29 & 2 \\
\hline $\begin{array}{l}\text { University of Southern California, Los } \\
\text { Angeles, CA, United States }\end{array}$ & 3 & 82 & 27 & 0 \\
\hline $\begin{array}{l}\text { University of the West of England, } \\
\text { United Kingdom }\end{array}$ & 3 & 79 & 26 & 2 \\
\hline $\begin{array}{l}\text { Department of computer science, } \\
\text { Comsats University Islamabad, } \\
\text { Islamabad, 44000, Pakistan }\end{array}$ & 3 & 40 & 13 & 0 \\
\hline $\begin{array}{l}\text { Department of security studies and } \\
\text { criminology, Macquarie University, } \\
\text { Sydney, Australia }\end{array}$ & 3 & 21 & 7 & 0 \\
\hline
\end{tabular}

From Table 4.2, we can see that the University of Surrey (UK) had three publications, and those publications have received the highest number of citations per publication. In contrast, the University of Southern California (USA) had the same number of publications, but it had fewer citations per publication, which shows that the University of Surrey has marginally more impactful publications. This conclusion can be seen visually on the size of the density visualization of Figure 4.3, with the University of Surrey having the largest circle compared with the remaining universities.

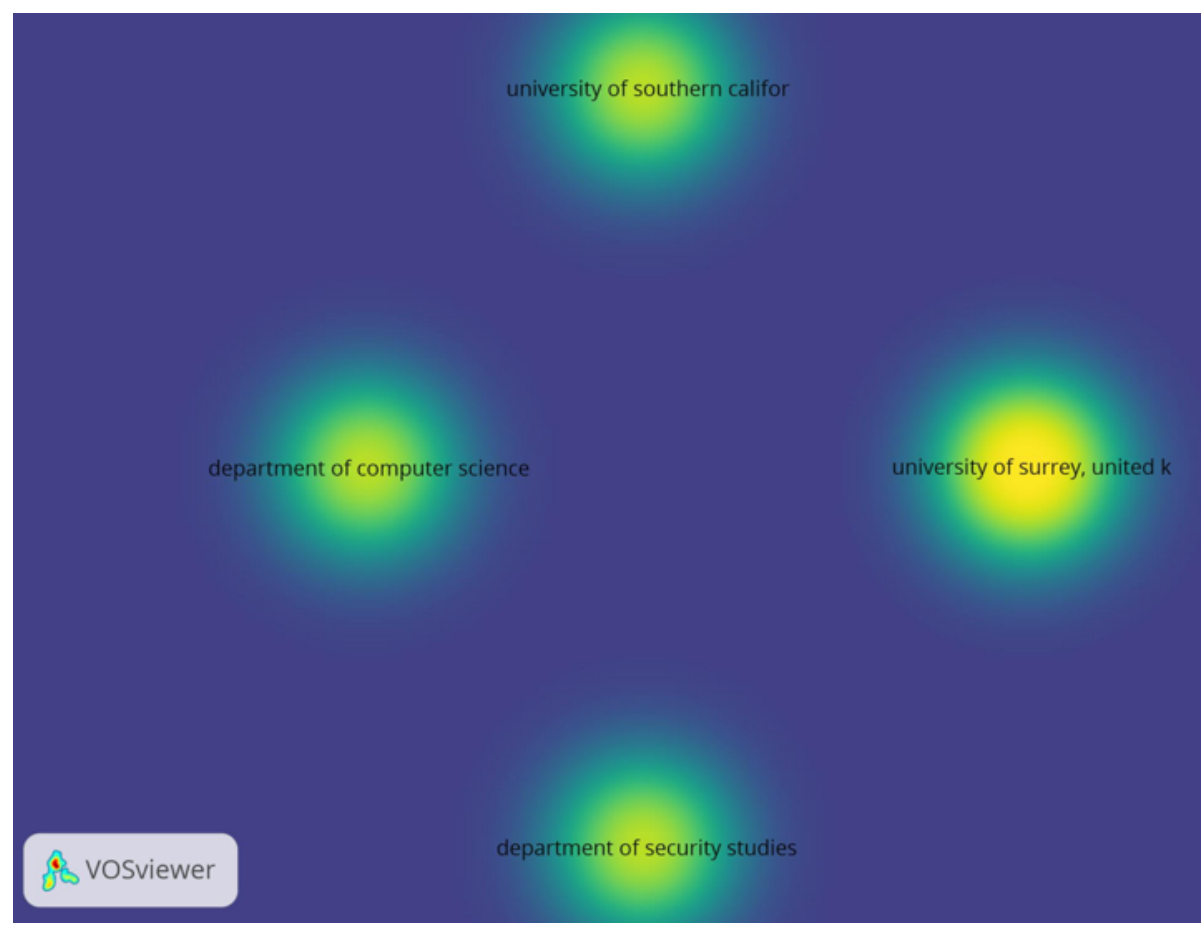

Figure 4.3 - The Density Visualization

\section{Authors' Citation}

The analysis for authors' citations used a minimum threshold of three documents by an author, which produced 18 authors that met this threshold out of 1278 authors (as can be seen from Figures 4.4 and 4.5 ). 


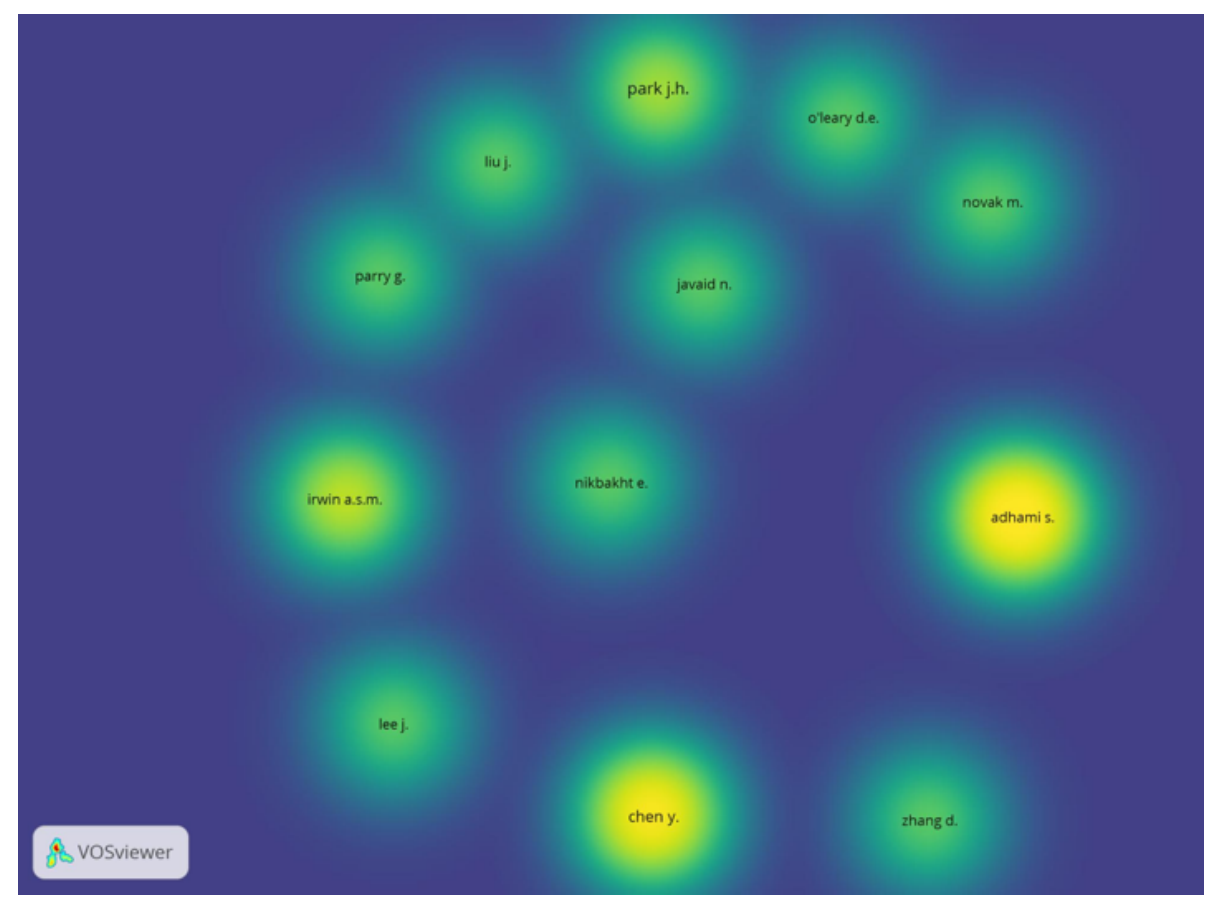

Figure 4.4- Density Visualization of Authors' Citations

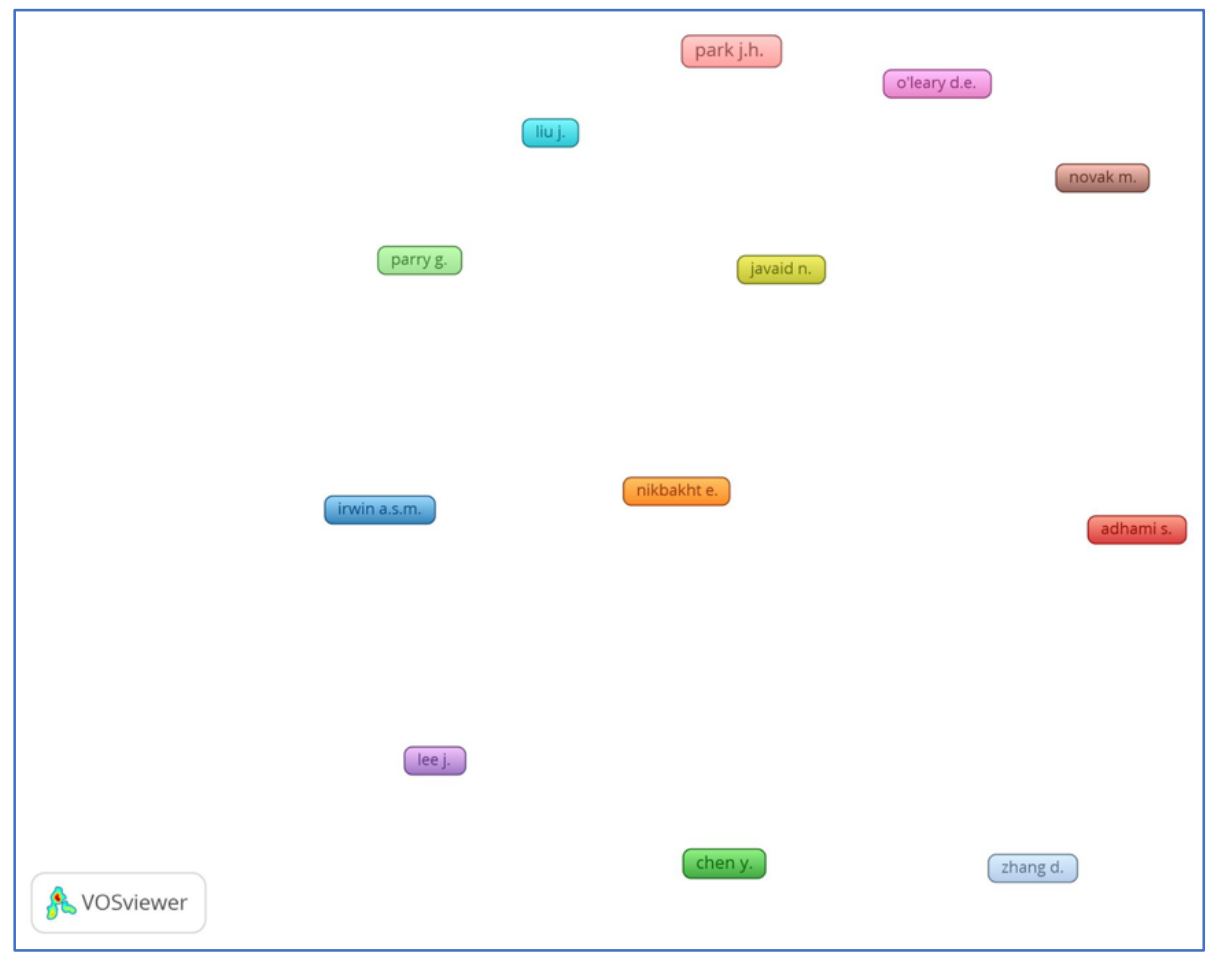

Figure 4.5 - Authors and Co-Authors' Relationship of The Researchers Who Are Working on the Blockchain Topics

Note: Authors who have published at least three documents were considered 
Table 4.3 - Author's Documents and Associated Citations

\begin{tabular}{|l|c|c|c|l|c|c|c|}
\hline Author & Documents & Citations & $\begin{array}{c}\text { Total Link } \\
\text { Strength }\end{array}$ & Author & Documents & Citations & $\begin{array}{c}\text { Total Link } \\
\text { Strength }\end{array}$ \\
\hline Park J.H. & 5 & 47 & 0 & Adhami S. & 3 & 150 & 12 \\
\hline Chen Y. & 4 & 18 & 1 & Giudici G. & 3 & 149 & 13 \\
\hline Adhami S. & 3 & 150 & 12 & Martinazzi S. & 3 & 136 & 11 \\
\hline Giudici G. & 3 & 149 & 13 & Li X. & 3 & 134 & 2 \\
\hline Irwin A.S.M. & 3 & 49 & 2 & Parry G. & 3 & 97 & 0 \\
\hline Javaid N. & 3 & 40 & 0 & O'leary D.E. & 3 & 82 & 0 \\
\hline Lee J. & 3 & 32 & 0 & Irwin A.S.M. & 3 & 49 & 2 \\
\hline Li X. & 3 & 134 & 2 & Park J.H. & 5 & 47 & 0 \\
\hline Liu J. & 3 & 17 & 0 & Vismara S. & 3 & 44 & 8 \\
\hline Martinazzi S. & 3 & 136 & 11 & Javaid N. & 3 & 40 & 0 \\
\hline Nikbakht E. & 3 & 2 & 0 & Lee J. & 3 & 32 & 0 \\
\hline Novak M. & 3 & 18 & 0 & Chen Y. & 4 & 18 & 1 \\
\hline O'leary D.E. & 3 & 82 & 0 & Novak M. & 3 & 18 & 0 \\
\hline Parry G. & 3 & 97 & 0 & Liu J. & 3 & 17 & 0 \\
\hline Turner A.B. & 3 & 11 & 2 & Turner A.B. & 3 & 11 & 2 \\
\hline Vismara S. & 3 & 44 & 8 & Wang D. & 3 & 3 & 1 \\
\hline Wang D. & 3 & 3 & 1 & Nikbakht E. & 3 & 2 & 0 \\
\hline Zhang D. & 3 & 2 & 0 & Zhang D. & 3 & 2 & 0 \\
\hline
\end{tabular}

Regarding article publishing, we see that Park, J.H. is leading the most published articles with five articles, followed closely with four articles by Chen, Y. and Adhami, S. with three articles. However, although Adhami, S. had produced the average number of 3 articles, his articles were cited the most with 150 citations, followed closely by Giudici, G. with 149 citations. Adhami and Giudici papers had better quality and research information. However, when the threshold is reduced from 3 to 2 articles, the number of authors that meet the threshold increase to 98 out of 1278, and we get another picture as shown in Table 4.4. Considering Table 4.4 below, we can see that Wang Y. is leading with an average citation of 76, followed by Wang J. with an average citation of 58.5. We see that Adhami S. and Giudici G. take the fifth and sixth position in the average citations score of 50 and 49.67, respectively. Therefore, we can conclude that the picture of which author publishes more quality papers cited by other authors differs when we set the minimum number of articles published.

Table 4.4 - The Author's Average Citations (First Ten Entries)

\begin{tabular}{|l|c|c|c|c|c|}
\hline \multicolumn{1}{|c|}{ Author } & $\begin{array}{l}\text { Weight } \\
\text { <Links }>\end{array}$ & $\begin{array}{l}\text { weight }<\text { Total } \\
\text { link strength }>\end{array}$ & $\begin{array}{l}\text { weight } \\
\text { <Documents }>\end{array}$ & $\begin{array}{l}\text { weight } \\
\text { <Citations }>\end{array}$ & $\begin{array}{l}\text { score <Avg. } \\
\text { citations }>\end{array}$ \\
\hline Wang Y. & 8 & 8 & 2 & 152 & 76 \\
\hline Wang J. & 3 & 3 & 2 & 117 & 58.5 \\
\hline Kouhizadeh M. & 6 & 8 & 2 & 108 & 54 \\
\hline Sarkis J. & 6 & 8 & 2 & 108 & 54 \\
\hline Adhami S. & 13 & 31 & 3 & 150 & 50 \\
\hline Giudici G. & 13 & 36 & 3 & 149 & 49.6667 \\
\hline Martinazzi S. & 13 & 31 & 3 & 136 & 45.3333 \\
\hline Li X. & 9 & 11 & 3 & 134 & 44.6667 \\
\hline Adams R. & 7 & 7 & 2 & 78 & 39 \\
\hline Parry G. & 7 & 7 & 3 & 97 & 32.3333 \\
\hline
\end{tabular}




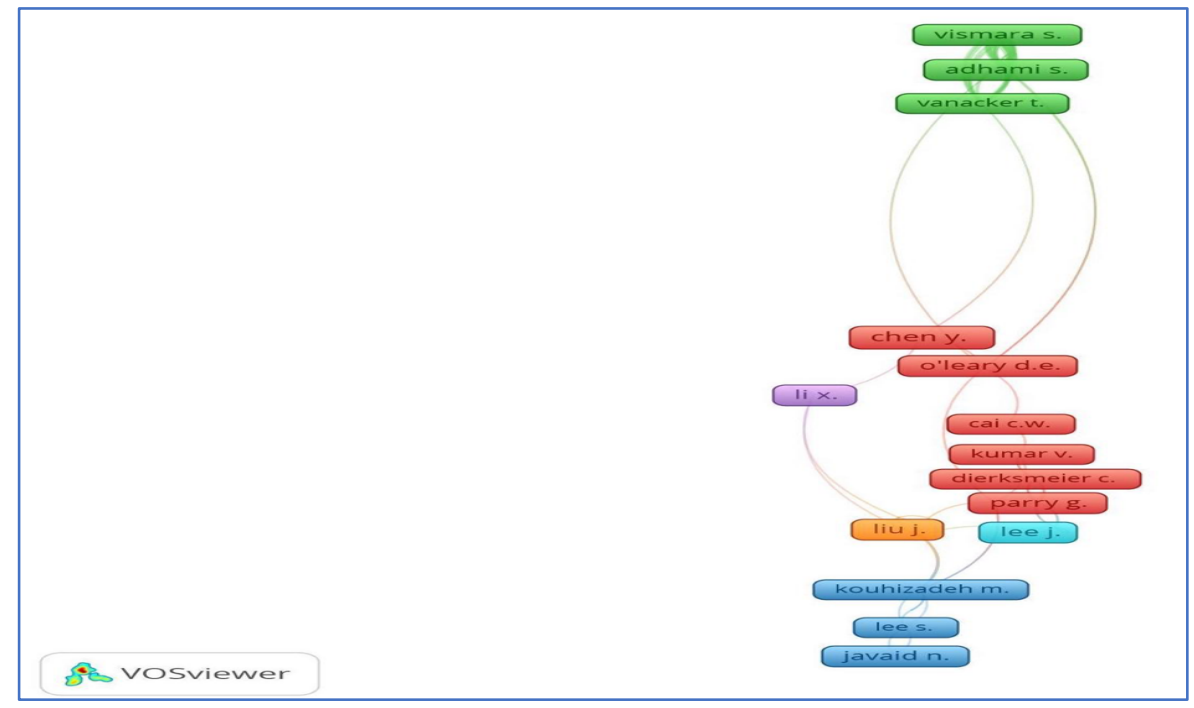

Figure 4.6 - Authors and Co-Authors Relationship of The Researchers Who Are Working on the Blockchain Topics Notes: Authors who have published at least two documents were considered

It is not surprising to see that from the co-citation analysis that Nakamoto (2008) has the most oversized box representing the most extensive citation, as Satoshi Nakamoto was the one who started the white paper on blockchain topic as we can see from Figure 4.7 and Table 4.5. In addition, we can also see that there are predominantly 3 clusters that are citing each other (each color representing one cluster in Figure 4.7) and Table 4.5.

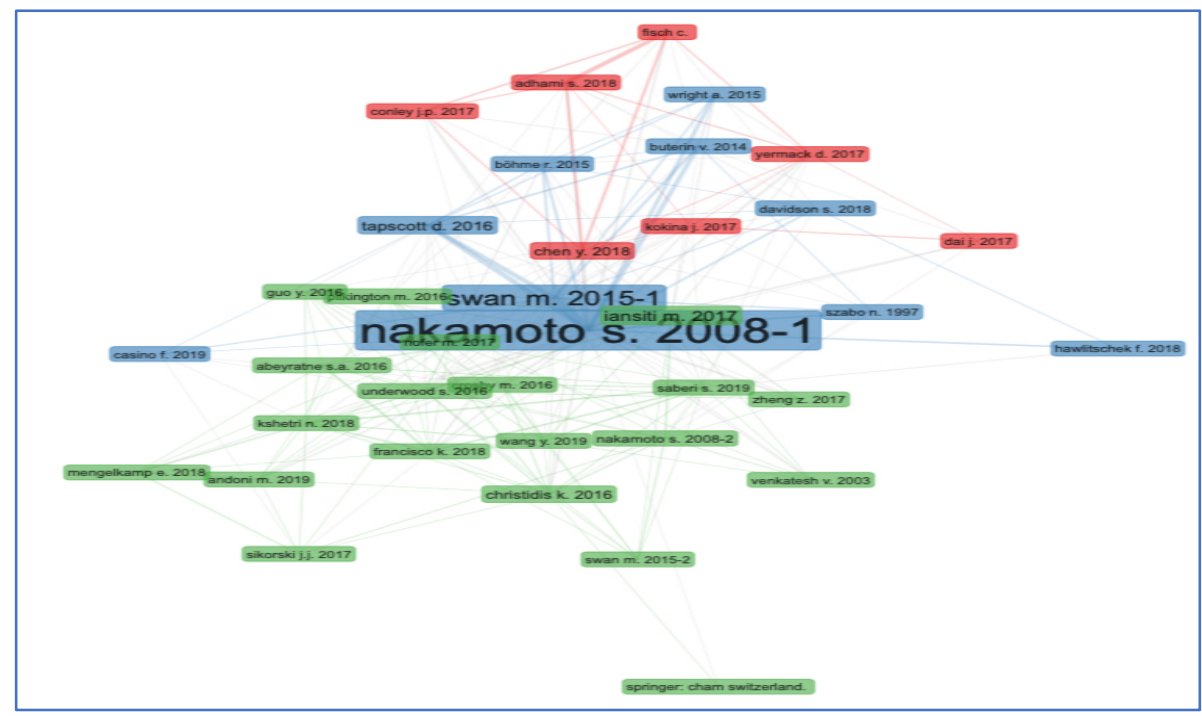

Figure 4.7 - Co-Citation Network 
Table 4.5 - Co-Citation Network Clusters (3 Clusters)

\begin{tabular}{|c|c|c|c|c|c|}
\hline \# & Node & Cluster & Betweenness & Closeness & PageRank \\
\hline 1 & Nakamoto S. 2008-1 & 1 & 307.45 & 0.02 & 0.12 \\
\hline 2 & Swan M. 2015-1 & 1 & 49.54 & 0.02 & 0.06 \\
\hline 3 & Tapscott D. 2016 & 1 & 4.51 & 0.01 & 0.03 \\
\hline 4 & Yermack D. 2017 & 1 & 2.53 & 0.01 & 0.02 \\
\hline 5 & Adhami S. 2018 & 1 & 2.62 & 0.01 & 0.02 \\
\hline 6 & Chen Y. 2018 & 1 & 17.45 & 0.02 & 0.03 \\
\hline 7 & Buterin V. 2014 & 1 & 2.69 & 0.01 & 0.03 \\
\hline 8 & Fisch C. & 1 & 0.44 & 0.01 & 0.02 \\
\hline 9 & Dai J. 2017 & 1 & 0.67 & 0.01 & 0.01 \\
\hline 10 & Böhme R. 2015 & 1 & 4.35 & 0.01 & 0.02 \\
\hline 11 & Szabo N. 1997 & 1 & 0.23 & 0.01 & 0.01 \\
\hline 12 & Davidson S. 2018 & 1 & 4.02 & 0.01 & 0.02 \\
\hline 13 & Kokina J. 2017 & 1 & 2.86 & 0.01 & 0.02 \\
\hline 14 & Wright A. 2015 & 1 & 0.23 & 0.01 & 0.02 \\
\hline 15 & Hawlitschek F. 2018 & 1 & 0.19 & 0.01 & 0.01 \\
\hline 16 & Casino F. 2019 & 1 & 0.39 & 0.01 & 0.01 \\
\hline 17 & Conley J.P. 2017 & 1 & 0.59 & 0.01 & 0.02 \\
\hline 18 & Iansiti M. 2017 & 2 & 30.00 & 0.02 & 0.04 \\
\hline 19 & Christidis K. 2016 & 2 & 39.38 & 0.02 & 0.03 \\
\hline 20 & Nakamoto S. 2008-2 & 2 & 20.11 & 0.02 & 0.02 \\
\hline 21 & Zheng Z. 2017 & 2 & 8.37 & 0.01 & 0.02 \\
\hline 22 & Andoni M. 2019 & 2 & 1.58 & 0.01 & 0.02 \\
\hline 23 & Pilkington M. 2016 & 2 & 3.44 & 0.01 & 0.02 \\
\hline 24 & Underwood S. 2016 & 2 & 18.37 & 0.02 & 0.03 \\
\hline 25 & Springer: Cham Switzerland. & 2 & 0.00 & 0.01 & 0.01 \\
\hline 26 & Sikorski J.J. 2017 & 2 & 4.59 & 0.01 & 0.02 \\
\hline 27 & Swan M. 2015-2 & 2 & 1.83 & 0.01 & 0.01 \\
\hline 28 & Mengelkamp E. 2018 & 2 & 7.09 & 0.01 & 0.02 \\
\hline 29 & Nofer M. 2017 & 2 & 5.80 & 0.01 & 0.02 \\
\hline 30 & Pop C. 2018 & 2 & 0.83 & 0.01 & 0.01 \\
\hline 31 & Wood G. 2014 & 2 & 0.32 & 0.01 & 0.01 \\
\hline 32 & Saberi S. 2019 & 3 & 21.03 & 0.02 & 0.03 \\
\hline 33 & Crosby M. 2016 & 3 & 8.23 & 0.01 & 0.02 \\
\hline 34 & Francisco K. 2018 & 3 & 9.21 & 0.02 & 0.03 \\
\hline 35 & Kshetri N. 2018 & 3 & 11.87 & 0.02 & 0.03 \\
\hline 36 & Abeyratne S.A. 2016 & 3 & 1.99 & 0.01 & 0.02 \\
\hline 37 & Guo Y. 2016 & 3 & 3.19 & 0.01 & 0.02 \\
\hline 38 & Venkatesh V. 2003 & 3 & 0.45 & 0.01 & 0.01 \\
\hline 39 & Wang Y. 2019 & 3 & 6.98 & 0.01 & 0.02 \\
\hline 40 & Kouhizadeh M. 2018 & 3 & 1.67 & 0.01 & 0.02 \\
\hline 41 & Tapscott D. 2017 & 3 & 0.26 & 0.01 & 0.01 \\
\hline 42 & Treiblmaier H. 2018 & 3 & 3.65 & 0.01 & 0.02 \\
\hline
\end{tabular}

\section{Authors' Countries}

When we used the analysis of authors' countries with a minimum of 5 articles, 36 countries met this threshold out of 79 countries. However, we reduced the minimum article number to 3 articles; 48 countries out of the 79 countries met the threshold.

From the analyzed data, we see that the USA has the highest number of publications of 92 documents, seconded by the UK with 59 documents, followed by China with 50 documents, while Germany and South Korea are close to each other with 42 and 40 documents respectively. Australia and Russian Federation share the same position with 31 documents, except Australia had a higher number of citations (279 compared to 77). Table 4.6 below 
shows this information, and -as we have established earlier- the number of publications each country produces is not an indication of the quality and impact, and in this case, cited publications by other authors worldwide. A noticeable example is that both Australia and Russian Federation produced 31 documents but the citations that Australia's documents have raised 279 citations compared with 77 citations raised by the Russian Federation's documents.

Table 4.6 - The 25 Countries Producing Highest Citations

\begin{tabular}{|l|c|c|c|}
\hline \multicolumn{1}{|c|}{ Country } & Documents & Citations & $\begin{array}{c}\text { Total Link } \\
\text { Strength }\end{array}$ \\
\hline United States & 92 & 1014 & 9878 \\
\hline United Kingdom & 59 & 709 & 8157 \\
\hline China & 50 & 640 & 4867 \\
\hline Germany & 42 & 395 & 7489 \\
\hline South Korea & 40 & 297 & 4375 \\
\hline Australia & 31 & 279 & 2706 \\
\hline Italy & 28 & 247 & 4739 \\
\hline Canada & 12 & 222 & 2674 \\
\hline Hong Kong & 7 & 204 & 596 \\
\hline France & 10 & 130 & 2556 \\
\hline Romania & 6 & 117 & 933 \\
\hline India & 15 & 108 & 2129 \\
\hline Netherlands & 15 & 107 & 2553 \\
\hline Belgium & 12 & 97 & 2026 \\
\hline Poland & 8 & 89 & 848 \\
\hline Switzerland & 12 & 83 & 1387 \\
\hline Russian Federation & 31 & 77 & 1021 \\
\hline Ireland & 9 & 77 & 1622 \\
\hline Singapore & 8 & 75 & 730 \\
\hline Hungary & 3 & 68 & 218 \\
\hline Pakistan & 8 & 66 & 1301 \\
\hline Saudi Arabia & 7 & 63 & 1261 \\
\hline Ukraine & 9 & 43 & 226 \\
\hline Norway & 4 & 42 & 1462 \\
\hline Spain & 12 & 32 & 1376 \\
\hline
\end{tabular}

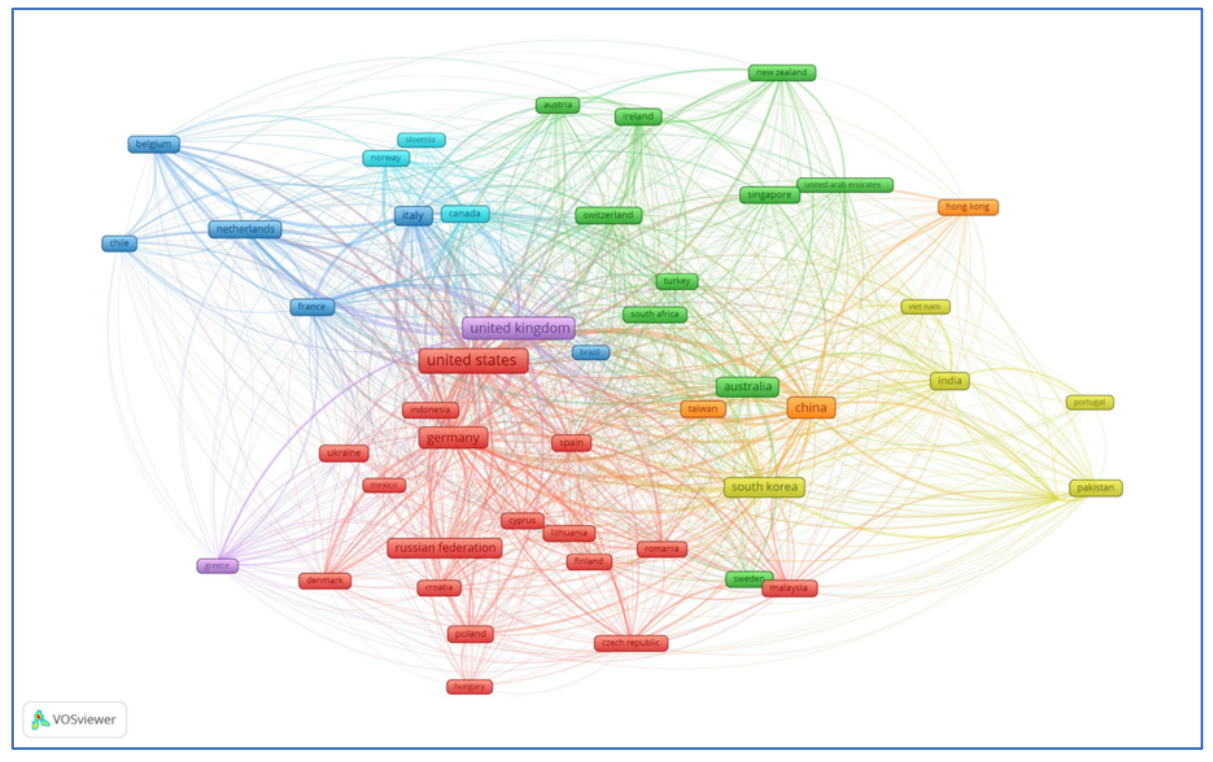

Figure 4.8 - Countries Publications Network Map 


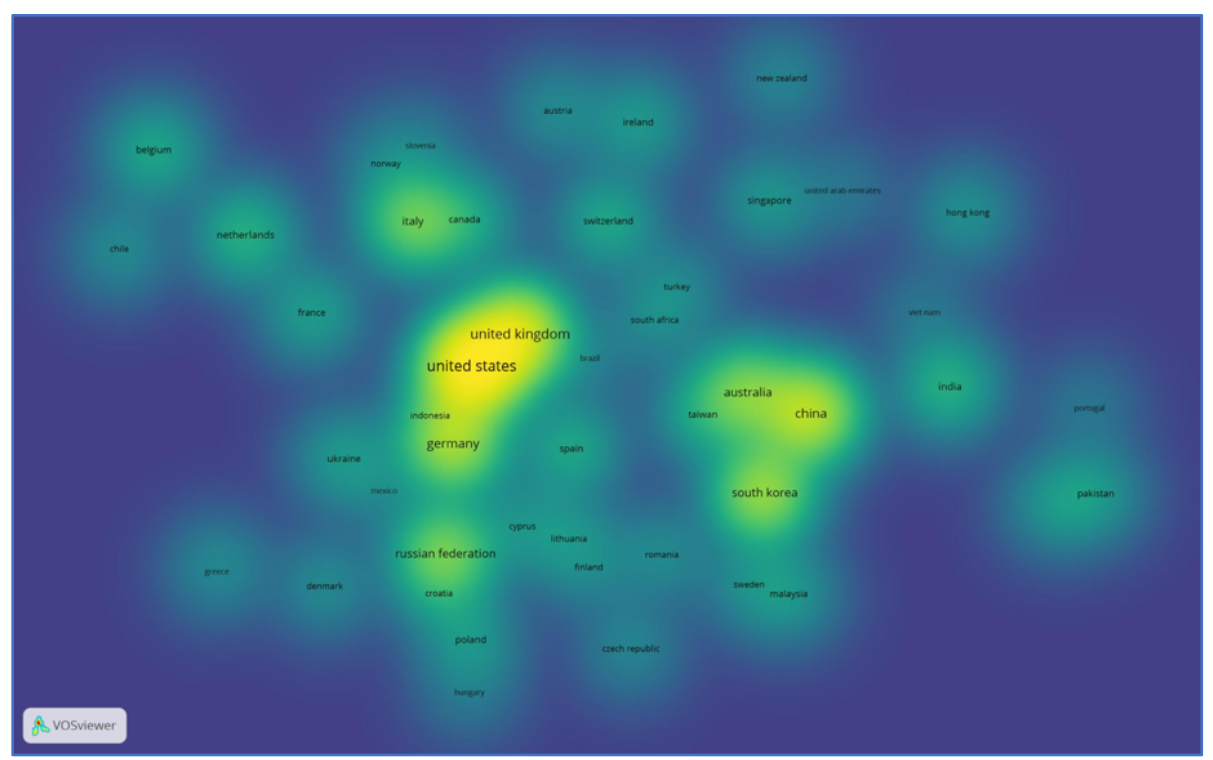

Figure 4.9- Countries Publications Density Map

In addition, Figure 4.8 shows each country's number of publications, and the larger the box, the more the number of publications. We can see clearly that the USA and UK are leading in that Figure. Moreover, Figure 4.9 shows the density of those countries' publications. We can see the more significant density is in the USA, UK, and China, which comes as no surprise when evaluating Table 4.6.

\section{Collaboration Between Countries}

Figure 4.10 shows the network of collaboration between countries working together. We see 30 different clusters, and we see that the United Kingdom is collaborating the most and that its clusters include European Countries as well as Switzerland and Turkey. We also see that Australia collaborates mainly in its cluster with New Zealand and India and UK and China outside its cluster. The USA collaborates with other clusters with more collaboration with its cluster (i.e., cluster 1), including Canada, Mexico, Chile, Colombia, and Croatia.

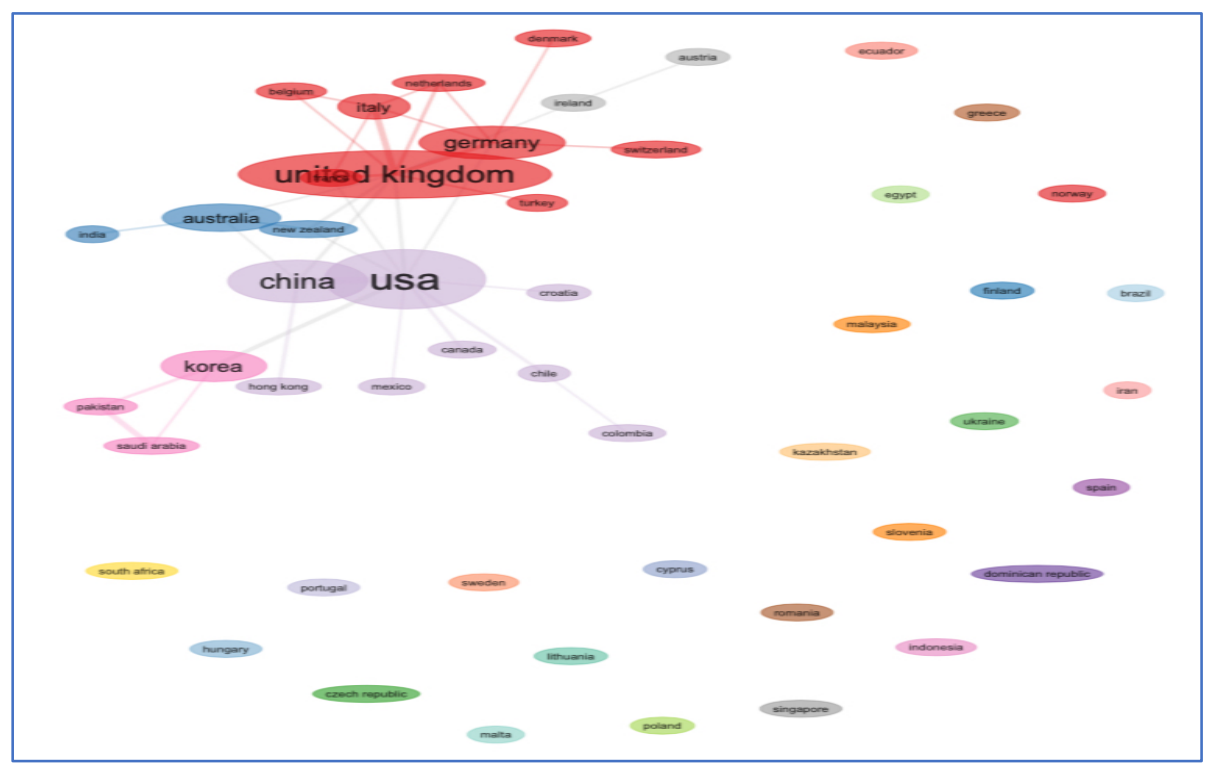

Figure 4.10 - Collaboration between Countries (Overall) 
This collaboration can be seen in Table 4.7 below, which shows each cluster's members. We can visualize that the collaboration between countries is the highest in clusters 1 and 2 .

Table 4.7 - Highest 20 Collaborating Countries Network

\begin{tabular}{|l|l|c|c|}
\hline ID & Node & Cluster & Betweenness \\
\hline 1 & United Kingdom & 1 & 126.5 \\
\hline 2 & Germany & 1 & 49.3 \\
\hline 3 & Italy & 1 & 2.7 \\
\hline 4 & Netherlands & 1 & 0.0 \\
\hline 5 & Switzerland & 1 & 0.0 \\
\hline 6 & Turkey & 1 & 0.0 \\
\hline 7 & France & 1 & 1.6 \\
\hline 8 & Belgium & 1 & 0.0 \\
\hline 9 & Denmark & 1 & 0.0 \\
\hline 10 & Australia & 2 & 23.3 \\
\hline 11 & India & 2 & 0.0 \\
\hline 12 & New Zealand & 2 & 3.0 \\
\hline 13 & Ukraine & 3 & 0.0 \\
\hline 14 & Spain & 4 & 0.0 \\
\hline 15 & Malaysia & 5 & 0.0 \\
\hline 16 & Romania & 6 & 0.0 \\
\hline 17 & Korea & 7 & 44.0 \\
\hline 18 & Pakistan & 7 & 0.0 \\
\hline 19 & Saudi Arabia & 7 & 0.0 \\
\hline 20 & Singapore & 8 & 0.0 \\
\hline
\end{tabular}

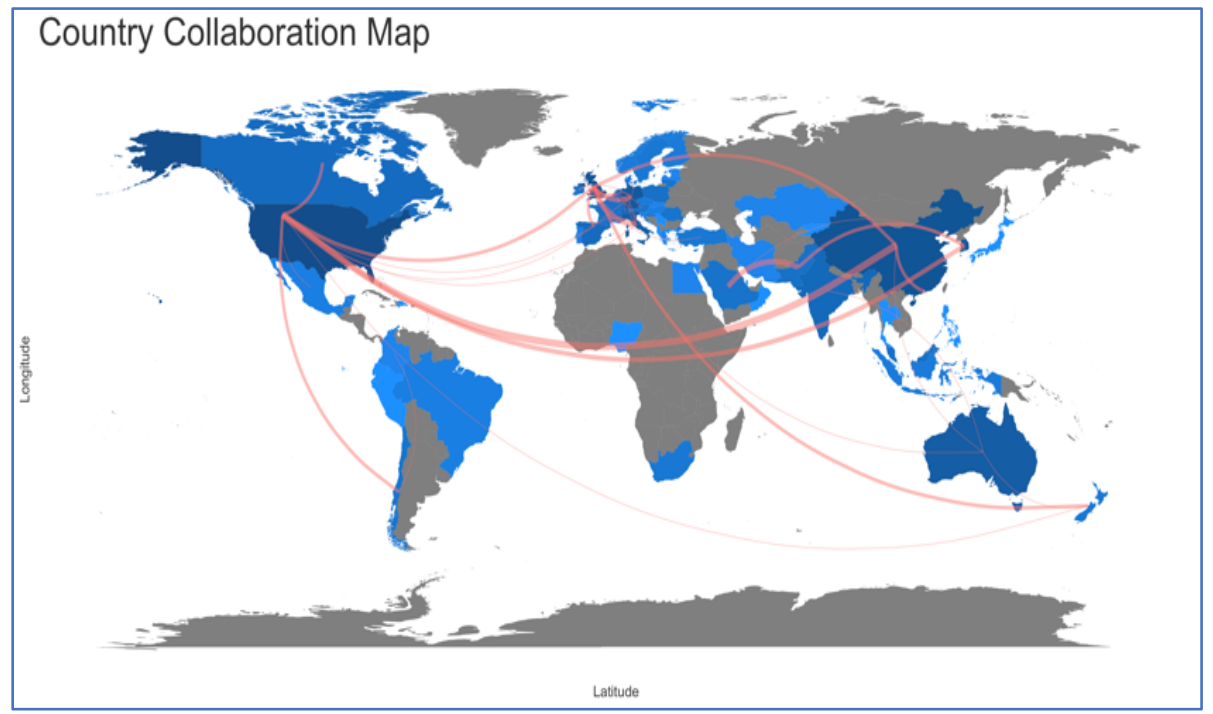

Figure 4.11 - Map of Country Collaboration

The collaboration of authors' countries can be seen from Figure 4.11, where we can see the collaboration lines (pink in color). The country color represents the number of publications, the darker the blue color, the more publications the country has. This finding of the collaboration between countries is consistent with what was concluded earlier. For example, there are lines from Australia to New Zealand, India, China, and the UK.

\section{Most Cited Documents Network}

Table 4.8 lists the 20 most cited titles, the publishing journal, the author, and the total citation for each title. As confirmed from Table 3.1, we see that Financial Innovation is in the first position, with a title that raised 189 citations. It is also in $13^{\text {th }}, 14^{\text {th }}$, and $16^{\text {th }}$ positions with other titles. We also note that 19 out of those 20 titles are written by collaborating authors 
range from one to four. This aligns with the growing number of co-authors per paper and the continual declining of self-citation rate which benefit the topic of blockchain applications (Liu et al, 2019).

Table 4.8 - Most 20 Global Cited Documents

\begin{tabular}{|c|c|c|c|}
\hline \# & Paper & Title & $\begin{array}{c}\text { Total } \\
\text { Citations }\end{array}$ \\
\hline 1 & SUN J, 2016, FINANCIAL INNOV & $\begin{array}{l}\text { Blockchain-based sharing services: What } \\
\text { blockchain technology can contribute to } \\
\text { smart cities }\end{array}$ & 189 \\
\hline 2 & $\begin{array}{l}\text { KIM HM, 2018, INTELL SYST ACCOUNT } \\
\text { FINANCE MANAG }\end{array}$ & $\begin{array}{l}\text { Toward an ontology-driven blockchain } \\
\text { design for supply-chain provenance }\end{array}$ & 182 \\
\hline 3 & $\begin{array}{l}\text { DAGHER GG, 2018, SUSTAINABLE CITIES } \\
\text { SOC }\end{array}$ & $\begin{array}{l}\text { Ancile: Privacy-preserving framework for } \\
\text { access control and interoperability of } \\
\text { electronic health records using blockchain } \\
\text { technology }\end{array}$ & 168 \\
\hline 4 & ADHAMI S, 2018, J ECON BUS & $\begin{array}{l}\text { Why do businesses go crypto? An } \\
\text { empirical analysis of initial coin offerings }\end{array}$ & 135 \\
\hline 5 & LI X, 2017, DECIS SUPPORT SYST & $\begin{array}{l}\text { The technology and economic } \\
\text { determinants of cryptocurrency exchange } \\
\text { rates: The case of Bitcoin }\end{array}$ & 132 \\
\hline 6 & WANG Y, 2019, INT J PROD ECON & $\begin{array}{l}\text { Making sense of blockchain technology: } \\
\text { How will it transform supply chains? }\end{array}$ & 105 \\
\hline 7 & WARNER KSR, 2019, LONG RANGE PLANN & $\begin{array}{l}\text { Building dynamic capabilities for digital } \\
\text { transformation: An ongoing process of } \\
\text { strategic renewal }\end{array}$ & 95 \\
\hline 8 & KOUHIZADEH M, 2018, SUSTAINABILITY & $\begin{array}{l}\text { Blockchain Practices, Potentials, and } \\
\text { Perspectives in Greening Supply Chains }\end{array}$ & 87 \\
\hline 9 & SHERMIN V, 2017, STRATEG CHANGE & $\begin{array}{l}\text { Disrupting governance with blockchains } \\
\text { and smart contracts }\end{array}$ & 71 \\
\hline 10 & WU J, 2018, SUSTAINABILITY & $\begin{array}{l}\text { The invisible politics of Bitcoin: } \\
\text { governance crisis of a decentralised } \\
\text { infrastructure }\end{array}$ & 70 \\
\hline 11 & DE FILIPPI P, 2016, INTERNET POLICY REV & $\begin{array}{l}\text { The invisible politics of Bitcoin: } \\
\text { governance crisis of a decentralised } \\
\text { infrastructure }\end{array}$ & 69 \\
\hline 12 & NOWIŃSKI W, 2017, ENTREP BUS ECON REV & $\begin{array}{l}\text { How Can Blockchain Technology Disrupt } \\
\text { the Existing Business Models? }\end{array}$ & 68 \\
\hline 13 & XU JJ, 2016, FINANCIAL INNOV & $\begin{array}{l}\text { Are blockchains immune to all malicious } \\
\text { attacks? }\end{array}$ & 68 \\
\hline 14 & WANG H, 2016, FINANCIAL INNOV & A maturity model for blockchain adoption & 65 \\
\hline 15 & $\begin{array}{l}\text { O'LEARY DE, 2017, INTELL SYST ACCOUNT } \\
\text { FINANCE MANAG }\end{array}$ & $\begin{array}{l}\text { Configuring blockchain architectures for } \\
\text { transaction information in blockchain } \\
\text { consortiums: The case of accounting and } \\
\text { supply chain systems }\end{array}$ & 63 \\
\hline 16 & CAI Y, 2016, FINANCIAL INNOV & $\begin{array}{l}\text { Fraud detections for online businesses: a } \\
\text { perspective from blockchain technology }\end{array}$ & 58 \\
\hline 17 & FU B, 2018, SUSTAINABILITY & $\begin{array}{l}\text { Blockchain Enhanced Emission Trading } \\
\text { Framework in Fashion Apparel } \\
\text { Manufacturing Industry }\end{array}$ & 51 \\
\hline 18 & SCOTT B, 2017, STRATEG CHANGE & $\begin{array}{l}\text { Exploring the rise of blockchain } \\
\text { technology: Towards distributed } \\
\text { collaborative organizations }\end{array}$ & 50 \\
\hline 19 & LI Z, 2019, ELECTR J & $\begin{array}{l}\text { Blockchain for decentralized transactive } \\
\text { energy management system in networked } \\
\text { microgrids }\end{array}$ & 49 \\
\hline 20 & DIERKSMEIER C, 2018, J BUS ETHICS & Cryptocurrencies and Business Ethics & 49 \\
\hline
\end{tabular}




\section{CONCLUSION \& RECOMMENDATION}

After more than ten years of inventing the blockchain, we see that the scientific community had been continuously writing in the different fields that can use the blockchain and its applications. From cryptocurrencies to smart contracts to smart cities and sustainability, the paper explores all the areas within their specialization to analyze, evaluate and innovate blockchain usage to increase efficiency, trust, and cost savings. Economy and finance had been a prime mover in the movement of advancing applications using the blockchain.

From the findings of this study, we found that Satoshi Nakamoto's white paper had started the movement of using blockchain, and it is considered from the bibliometric analysis to be one of the most referenced papers. Still, at this time, other topics are leading the publication's statistics, as can be seen from this study. In the overall publication, we found that subject areas of the publications in blockchain had been led by Computer Science and followed by Engineering, Decision Science, and Mathematics. Conference papers had also led the type of publications in blockchain in the majority, with article types as the second position. The publication in the blockchain has been led by China, followed by the USA, India, UK, and Germany (in sequence). However, once we applied certain filters such as the publication language to be English, selected subject areas (related to business and economics), specified that the publication type to journal articles (thus eliminating conference papers), there were apparent shifts in the numbers and countries' positions. One thing that stayed the same (without or with filters) was that publishing journal articles on the blockchain is increasing every year, as it can be visualized from the bibliometric analysis based on previous years.

Our study showed that the top authors are not only those who produce several publications but those whose publications generate a higher number of citations. This is the same finding that our study showed earlier with the publications by organizations or journal publishers. The number of average citations per document published gave the higher standing of the organization and not the number of publications. The importance of citations and average citation per document had clarified not only the most cited publication, the top organization, but it also showed the top country producing reputable quality publications in the field of blockchain. Initially, the data showed China leading the rest of the countries, with the USA following behind. With additional filtering to the search from the database source, we saw that the USA became the leader of the journal publications in the blockchain. With further analysis, we found that Hong Kong generated fewer papers than what the USA was producing. Still, those papers generated larger citation counts, making Hong Kong lead the countries as concluded from the bibliometric analysis. Our study showed by using the citation findings that the University of Surrey in the UK led other universities in the USA, the UK, Pakistan, and Australia.

The final finding of our study was the 20 most cited publications about blockchain based on the total citations that each had generated. The study had shown that the blockchain is a live topic that is increasing annually, with publications being written in different fields relating to the usage (or possible usage) of blockchain and its technology. We visualize from the finding that blockchains' publications are increasing annually as academics, researchers, and scientists are replacing traditional methods and tools with blockchain technologies. This increase in publication -among other results- is producing new ways to do business, create public records, innovate new governing tools, and discover more efficient supply-chain management tools. 
As we based this study on the finding of one database, our recommendation for future research is to extract the data from different database sources. Future research should use the search keywords and the filters this study used to build on our findings. Our recommendation for future blockchain bibliometric study, to use this study and develop financial applications such as real economy, finance, cash-transfer, payments systems, and development. Future research can also study blockchain tracking applications in humanitarian fields such as aid delivery and sustainable development goals achievements percentages.

Our study was about the research direction carried out in selected subject areas dealing with blockchain. We believe this study will be a valuable starting point for any future research in the field of blockchain. This is due to the information it recorded about the blockchain and the 20 most global papers written on the topic. From this perspective, we highly recommend reading this study by any researcher in the field of blockchain-related issues. The reading should be treated as a background information to give the researcher a starting point in the literature survey before embarking on the research journey.

\section{REFERENCES}

Agarwal, A., Durairajanayagam, D., Tatagari, S., Esteves, S. C., Harlev, A., Henkel, R., Roychoudhury, S., Homa, S., Puchalt, N. G., Ramasamy, R., Majzoub, A., Ly, K. D., Tvrda, E., Assidi, M., Kesari, K., Sharma, R., Banihani, S., Ko, E., Abu-Elmagd, M., ... Bashiri, A. (2016). Bibliometrics: Tracking research impact by selecting the appropriate metrics. Asian Journal of Andrology, 18(2), 296-309. https://doi.org/10.4103/1008-682X.171582

Ante, Lennart. "A Place next to Satoshi: Foundations of Blockchain and Cryptocurrency Research in Business and Economics." Scientometrics 124, no. 2 (August 1, 2020): 1305-33. https://doi.org/10.1007/s11192-020-03492-8.

Azer, S. A. (2015). The top-cited articles in medical education: A bibliometric analysis. Academic Medicine: Journal of the Association of American Medical Colleges, 90(8), 1147-1161. https://doi.org/10.1097/ACM.0000000000000780

Bibliometrics (1): Concepts in literature reviews-YouTube. (2018, 3 March). Research HUB. https://www.youtube.com/watch?v=wBux-te-uxE

Bibliometrix R Package. (n.d.). Retrieved 24 June 2021, from https://www.bibliometrix.org/ Biblioshiny. (n.d.). Retrieved 24 June 2021, from https://www.bibliometrix.org/Biblioshiny.html

Bornmann, Lutz, Robin Haunschild, and Rüdiger Mutz. "Should Citations Be FieldNormalized in Evaluative Bibliometrics? An Empirical Analysis Based on Propensity Score Matching." Journal of Informetrics 14, no. 4 (November 1, 2020): 101098. https://doi.org/10.1016/j.joi.2020.101098.

Carvalho, Gustavo Dambiski Gomes de, Carla Cristiane Sokulski, Wesley Vieira da Silva, Hélio Gomes de Carvalho, Rafael Vignoli de Moura, Antonio Carlos de Francisco, and Claudimar Pereira da Veiga. "Bibliometrics and Systematic Reviews: A Comparison between the Proknow-C and the Methodi Ordinatio." Journal of Informetrics 14, no. 3 (August 1, 2020): 101043. https://doi.org/10.1016/j.joi.2020.101043. 
Chen, X., Chen, J., Wu, D., Xie, Y., \& Li, J. (2016). Mapping the Research Trends by Coword Analysis Based on Keywords from Funded Project. Procedia Computer Science, 91, 547-555. https://doi.org/10.1016/j.procs.2016.07.140

Conway, L. (2020, 17 November). Blockchain Explained. Investopedia. https://www.investopedia.com/terms/b/blockchain.asp

Fetscherin, M., \& Heinrich, D. (2015). Consumer brand relationships research: A bibliometric citation meta-analysis. Journal of Business Research, 68(2), 380-390. https://doi.org/10.1016/j.jbusres.2014.06.010

Fetscherin, M., \& Usunier, J.-C. (2012). Corporate Branding: An Interdisciplinary Literature Review. European Journal of Marketing, 46, 733-753. https://doi.org/10.1108/03090561211212494

Firdaus, Ahmad, Mohd Faizal Ab Razak, Ali Feizollah, Ibrahim Abaker Targio Hashem, Mohamad Hazim, and Nor Badrul Anuar. "The Rise of 'Blockchain': Bibliometric Analysis of Blockchain Study.” Scientometrics 120, no. 3 (September 1, 2019): 12891331. https://doi.org/10.1007/s11192-019-03170-4.

Hughes, Alex, Andrew Park, Jan Kietzmann, and Chris Archer-Brown. "Beyond Bitcoin: What Blockchain and Distributed Ledger Technologies Mean for Firms." Business Horizons 62, no. 3 (May 1, 2019): 273-81. https://doi.org/10.1016/j.bushor.2019.01.002.

IGI Global. (n.d.). What is Bibliometric Analysis. Retrieved 22 March 2021, from https://www.igi-global.com/dictionary/education-literature-developmentresponsibility/2406

Lee, I.-S., Lee, H., Chen, Y.-H., \& Chae, Y. (2020). $<p>$ Bibliometric Analysis of Research Assessing the Use of Acupuncture for Pain Treatment Over the Past 20 Years $</ \mathrm{p}>$. Journal of Pain Research, 13, 367-376. https://doi.org/10.2147/JPR.S235047

Liu, Jiaying, Jiahao Tian, Xiangjie Kong, Ivan Lee, and Feng Xia. "Two Decades of Information Systems: A Bibliometric Review." Scientometrics 118, no. 2 (February 1, 2019): 617-43. https://doi.org/10.1007/s11192-018-2974-5.

McLellan, C. (2019, 2 December). How Blockchain Will Disrupt Business |ZDNet. https://www.zdnet.com/topic/how-blockchain-will-disrupt-business/

Muñoz-Leiva, F., Viedma, M. I., Sánchez-Fernández, J., \& López-Herrera, A. G. (2012). An application of co-word analysis and bibliometric maps for detecting the most highlighting themes in the consumer behaviour research from a longitudinal .... Quality and Quantity, 46, 1077-1095. https://doi.org/10.1007/s11135-011-9565-3

Nadzar, N. M. A. M., Bakri, A., \& Ibrahim, R. (2017). A bibliometric mapping of malaysian publication using co-word analysis. International Journal of Advances in Soft Computing and Its Applications, 9, 90-113.

Perianes-Rodriguez, Antonio, Ludo Waltman, and Nees Jan van Eck. "Constructing Bibliometric Networks: A Comparison between Full and Fractional Counting." Journal of Informetrics 10, no. 4 (November 1, 2016): 1178-95. https://doi.org/10.1016/j.joi.2016.10.006.

Pranckute, R. (2021). Web of Science (WoS) and Scopus: The Titans of Bibliographic Information in Today's Academic World. Publications, 9(1), 12. https://doi.org/10.3390/publications 9010012

Robinson-Garcia, Nicolás, Cassidy R. Sugimoto, Dakota Murray, Alfredo Yegros-Yegros, Vincent Larivière, and Rodrigo Costas. "The Many Faces of Mobility: Using Bibliometric Data to Measure the Movement of Scientists." Journal of Informetrics 13, no. 1 (February 1, 2019): 50-63. https://doi.org/10.1016/j.joi.2018.11.002.

ScienceDirect Topics. (n.d.). Bibliometric Study-An overview. Retrieved 6 March 2021, from https://www.sciencedirect.com/topics/computer-science/bibliometric-study 
Seglen, P., \& Aksnes, D. (2004). Scientific Productivity and Group Size: A Bibliometric Analysis of Norwegian Microbiological Research. Scientometrics, 49(1), 125-143. https://doi.org/10.1023/a:1005665309719

Shuaib, W., Acevedo, J. N., Khan, M. S., Santiago, L. J., \& Gaeta, T. J. (2015). The top 100 cited articles published in emergency medicine journals. The American Journal of Emergency Medicine, 33(8), 1066-1071. https://doi.org/10.1016/j.ajem.2015.04.047

Tandon, A., Kaur, P., Mäntymäki, M., \& Dhir, A. (2021). Blockchain applications in management: A bibliometric analysis and literature review. Technological Forecasting and Social Change, 166, 120649. https://doi.org/10.1016/j.techfore.2021.120649

Tchangalova, Nedelina. "Research Guides: Bibliometrics and Altmetrics: Measuring the Impact of Knowledge: Bibliometrics." Accessed 12 April 2021. https://lib.guides.umd.edu/bibliometrics/bibliometrics.

VOSviewer-Visualizing scientific landscapes. (n.d.). VOSviewer. Retrieved 24 June 2021, from https://www.vosviewer.com//

Who uses Scopus -Get started with Scopus | Elsevier solutions. (n.d.). Retrieved 24 June 2021, from https://www.elsevier.com/solutions/scopus/who-uses

Xu, M., Chen, X., \& Kou, G. (2019). A systematic review of blockchain. Financial Innovation, 5(1), 27. https://doi.org/10.1186/s40854-019-0147-z

Yuan, Fangfang, Jizhen Cai, Bin Liu, and Xiaowei Tang. "Bibliometric Analysis of 100 TopCited Articles in Gastric Disease." BioMed Research International 2020 (2020): 2672373. https://doi.org/10.1155/2020/2672373.

Zhang, Jiazhen. "Bibliometric Analysis | Encyclopedia." Accessed 12 April 2021. https://encyclopedia.pub/2024.

Zhao, J. L., Fan, S., \& Yan, J. (2016). Overview of business innovations and research opportunities in blockchain and introduction to the special issue. Financial Innovation, 2(1), 28. https://doi.org/10.1186/s40854-016-0049-2 